

\section{THE LIBRARY}

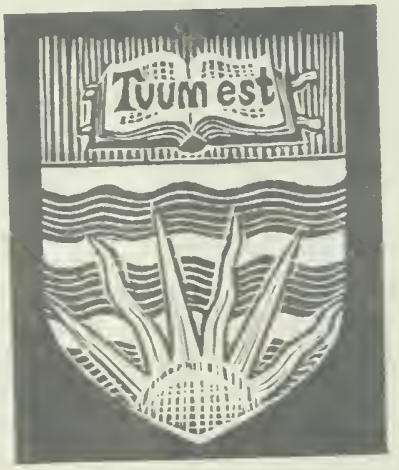

THE UNIVERSITY OF BRITISH COLUMBIA 



\title{
The Canadian \\ Seed Growers' Association and its work
}

\author{
INCLUDING THE \\ CONSTITUTION, BY-LAWS \\ AND \\ REGULATIONS
}

\author{
EDITED BY THE SECRETARY. AND \\ AUTHORIZED TO BE PRINTED AT \\ OTTAWA. FEB.. 1912
}


Digitized by the Internet Archive in 2010 with funding from University of British Columbia Library 


\section{GONTENTS.}

Some considerations regarding the seed question:-

Quantity of seed used annually in Canarla....

Average yields of farm crops in Canada.

Means of increasing proluction per acre

Good seed defined.

Concerning Choice of Variety

Concerning Choice of Seed of chosen variety

Treatment to prevent Loose Smut in oats.

Treatment to prevent Bunt in wheat.

Treament for barley Sunuts

Regarding the changing of seed.

Regarding degeneration in potatoes.

Principles of Plant Improvement..

System of seed selection for the farmer.

Importance of continued mass-selection cren in pure lines- 
The Canadian Seed Growers' Association and its Work:-

Origin and chief aim of the Association.

Organization of the Association .

Membership.

The work of the Ass'n and its relation to that of the Gov't. .

Funds.

General System of Seed Growing adopted by the Association :-

Choice of variety.

Production of "Elite Stock Seed" of chosen variety. .

The special seed plot as a means of obtaining Elite Stock Seed.

Annual use of a special seed plot

Classes of agricultural plants considered.

\section{Process of producing "Elite Stock Seed" by selection in case} of :- -

(a) Wheat, oats, barley, etc., (representing self-fertilizing

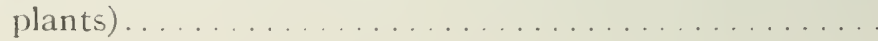

(b) Corn (representing plants which normally cross-fertilize)...

(c) Potatoes (representing vegetatively reproduced plants)

Main purposes served by the special seed plot (summary)

Regarding the multiplication of "Elite Stock Seed" .

Cultural conditions for secl growing....

Maintaining purity.

The cleaning and grading of seed 
Regarding the Registration of seed

Standards of quality and purity for "Registered Seed"

Weeds considered "Noxious" by Seed Control Act

Percentage germination standards

Regarding the commercial handling of "Registered Seed"

Inspection of seed intended for registration

Sealing of packages or sacks of "Registered Seed"

Seed Catalogue and the disposal of seed

Seed Exhibitions

Advantages of affiliation with the Association

Definition of Terms used by the Association

Constitution, By-laws, and Regulations of the Association

List of references on the work of seed growing, plant improvement, etc. 


\section{LIST OF ILLUSTRATIONS.}

FIg. I.-Experimental and Breeding Plots, O.A.C., Guelph, Ont....

FIG. II.-Special Seed Plot of Preston Wheat, grown from stock seed obtained from the Central Experimental Farm, Ottawa, Ont.

FIG. III.- "Hand-selected Seed Plot" and "Multiplying Field "

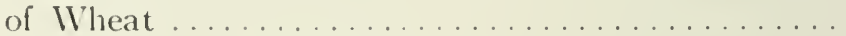

FIG. IV. - Diagrams showing variation in yield of individual rows of

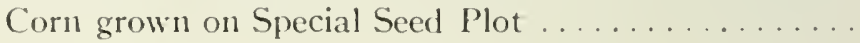

FIG. V.- Types of corn from different latitudes in Canada.

FIG. VI.-Diagrams showing the variation in yield of individual rows of potatoes grown on special plots ..........

FIc. VII.-Twelve most productive varieties of Potatoes at the Central Experimental Farm, Ottawa, after 5 years' test

Fin. VIII.-Certificate of Registration for "Registered Seed "' ...

FIG. IX.-Inspector examining a crop of Registered Seed Wheat produced on a "Multiplying Field " ............

Fir. X.- Score Card used by Inspector in connection with field inspection of cereal grains ...............

Fig. XI.-Front and back views of Registration Tags which are attached by the Association to packages or sacks of Registered Seed before these leave the premises of the grower

Fig. Xll.-Officer sealing sacks of Registered Seed Oats on the

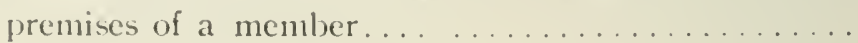

Fig. XIII.- Part of Exhibit of Selected Seed grown in Ontario and shown at the Winter Fair, Guelph, Dec., 1907 


\section{CANADIAN SEED GROWERS' ASSOCIATION}

Head Office: Canadian Building, Ottawa, Ont.

\section{Officers, 1912-13.}

President: James IV. Robertson, C.M.G., Ottawa, Ont.

Vice-Presidents: Prof. C. A. Zavitz, Guelph, Ont.; G. A. Gigault, Deputy Minister of Agriculture, Quebec; John Mooney, Regina, Sask.

Secretary and Treasurer: L. H. Newman, B.S.A., Canadian Building, Ottawa, Ontario.

Executive Council: Dr. Jas. Robertson, L. H. Newman, Prof. C. A. Zavitz, G. A. Gigault, Prof. L. S. Klinck, Macdonald College, Que.; Prof. Jno. Bracken, Agricultural College, Saskatoon, Sask.; Prof. M. Cumming, Agricultural College, Truro, N.S.

Directors: Prof. C. A. Zavitz; G. A. Gigault; Thomas S. Waugh, North Bedeque, P.E.I.; Jno. Mooney; J. O. Duke, Ruthren, Ont.; Wm. Thompson, London, Ont.; Prof. M. Cumming; WV. WT. Hubbard, Deputy Minister of Agriculture, Fredericton, N.B.; Prof. W. J. Black, M.A.C., Winnipeg, Man.: Prof. Klinck; Prof. John Bracken; George Harcourt, Deputy Minister of Agriculture, Edmonton, Alta.; J. IV. Wheaton, Toronto, Ont.; Donald Innes, Tobique River, N.B.; Prof. C. C. James, Toronto, Unt.; W. E. Scott, Deputy Minister of Agriculture, Victoria, B.C.; S. A. Bedford, M.A.C.. Winnipeg, Man.; George Batho, Winnipeg, Man.; Theodore Ross, Charlottetown, P.E.I.; W. R. Motherwell, Deputy Minister of Agriculture, Regina, Sask.

Auditors: L. S. Klinck, Macdonald College, Que.; Accomntant. Department of Agriculture, Ottawa, Ont.

Nort-Since the officers are elected by the Association annually, the above list is subject to change. 


\section{SOME CONSIDERATIONS REGARDING THE SEED QUESTION.}

Before discussing the work of the Association in detail, a few matters of general interest regarding the seed question as a whole will be considered.

According to the reports of the Census and Statistics Branch of the 1)epartment of Agriculture, over forty million bushels of seed are recpuired annually in Canada to produce our ordinary farm crops, namely Spring and Autumn wheat, oats, harley, pease, corn and potatoes. The amount used in cach Province is approximately as follows:-

Seed used annually in Canuda.

dicrage vields of firm crops in c'anuda.

Means of increasing produclion per ucre.
Alberta, $3 \frac{3}{4}$ million bushels; Manitoba, $3 \frac{3}{4}$ million bushels; Quebec, $5 \frac{1}{2}$ million bushels; Nova Scotia and Prince Edward Island, 800 thousand bushels each.

Notwithstanding the inmense total production realized from the above sowing, an examination of the returns reveals the significant fact that the average yield per acre is unnecessarily low as compared with that obtained by our best farmers. Thus the average yield of Spring Wheat per acre for all Canada is only about 19 bushels; that of oats 3.5 bushels, that of barley about 28 bushels, and that of potatoes about 124 bushels. Many of our best farmers grow from 25 to 35 luushels of wheat, trom 65 to 100 bushels of oats, from 40 to 50 bushels of barley and from 300 to 450 bushels of potatoes per acre. From this it is evident that the full producing power of the acre on the average farm is seldom reached. The production per acre may be increased in four ways, viz..-(1) By the improvement of soil fertility; (2) ly the improvement in methods of cultivation and crop rotation; (3) by the prevention of injury by weeds, insects and plant discases and (4) by the use of better seed. It is in the last of these various means of progress that the Canadian Seed Growers' Association is directly interested, although, in the prosecution of its work, the Association duly observes all of the essentials of successful crop raising.

Much has been said and written regarding the importance of good seerl. Numerous compilations from Experimental Station reports and elsewhere showing the superiority of such seed have been used in support of these arguments and various means have been and now are being taken to encourage the more general use of good seed throughout the country. It is only necessary however to visit onr local seed exhibitions or what is still more convincing, to examine the contents of the grain drill at seeding time (1) the average ('analian farm to fund tangible evidence of the fact that the (puality of seed which is still in common use is much inferior to what it hould he. The continued use of inferior seed is due to a variety of causes hut perbaps more especially of the failure of the average farmer himself to appreciate as fully as he should the part which the seed itself plays in deternining yield and quality in crops. The following elaboration of the 
various attributes of "Good Seed" should serve to emphasize the great importance, first of making a careful choice of variety and secondly of obtaining the best quality of seed of that variety.

Good Seed may be defined as follows:-

I. Seed belonging to a variety which is superior in the following respects, Good See viz:- -

1. Suitability for the conditions under which it is to be grown.

2. Yielding power.

3. Purity.

4. Quality of product for marketing or feeding purposes.

5. Hardiness.

(i. Strength of straw or stalk.

7. Ability to resist disease.

II. Seed which in itself is superior in the following respects, viz.:-

1. Vital energy.

2. Size and development of kernels.

3. Uniformity of sample as regards size and development of kernel.

4. Maturity.

5. Freedom from disease.

6. Freedom from other damage of any kind.

7. Freedom from weed seeds.

8. Freedom from seeds of other cultivated kinds or varieties.

\section{I.--Concerning Choice of Variety.}

1. The suitability of a sort for the conditions under which it is grou'n is a matter deserving of the most careful consideration. Certain sorts thrive better on clay soils than on soils which are lighter, and vice vers?; some thrive better on moist soils than others, while some may he less sensitive to soil and climatic conditions than are other sorts. Marked differences often exist between different sorts in regard to the number of das s required to attain maturity. U'uder certain conditions early maturing sorts are an advantage. Inder other conditions they are practically a necessity: The choice of a sort for a given district must depend largely upon circumstances. The great importance of choosing the hest available sort suggests at once the desirability of testing in local centres a number of those sorts which are most highly recommended by the Experimental Stations before leciding which should he grown as a main crop. Such tests may he conducted on certain furms in the locality. either under the direct supervision of an Experimental Siation or hy farmers themselves independently. When this choice has heen made. every effort should be put forth to linit the number of different 
sorts grown in the district, since where many sorts are grown it is extremely cifficult to maintain the purity of any one of them. Where a district is growing grain for seed, it will attain a reputation much more quickly where the number of sorts is limited than where many are being handled. The ability to purchase seed of any one variety in large quantities in a single centre is also a matter which appeals to the large buyer.

In order that local sort trials may give best results, the following points should be observed:-

(a) The plots should be laid out on as even and uniform soil as possible.

(b) They should be oblong in shape in order to equalize any variations in the character of the soil.

(c) Each plot should be at least ${ }_{100}^{1}$-acre in size. A plot $73^{\prime} \times 6^{\prime}$ is slightly more than $100^{1}$-acre in area, and is a convenient size to handle. All plots must of course be the same size and shape.

(d) Each sort to be tested should be allowed at least two separate plots which should be separated from each other by other plots. The importance of testing each sort in two or more plots, and of locating these some distance apart cannot be overestimated since experience shows that a fair judgment is scarcely to be expected from a single plot in view of inevitable differences which are to be found in the character of even our best soils. Assuming that a grower wishes to test four different sorts and that each sort is to be allowed as many as three different plots, these sorts, in the absence of variety names, may be labelled I-II-III and IV and the plots arranged in the following order: I-II-III-IV; I-II-III-IV; I-IIIII-IV. A fair expression of the yield of each sort may be obtained by averaging the returns from the three series in each case.

(e) The plots should be laid across the furrow and a space of at least two feet allowed between each plot.

(f) The sowing should be done with the greatest possible care. If possible, the seed, in the case of cereal grains, should be sown in drills as only in this way can an even stand be obtained.

(g) During the growing period, careful notes should be taken on the various points which are of interest in determining the value of a sort. The lates of seeding, heading out, and maturing, together with the strength of straw, presence of diseases and thickness of stand should all be noted.

(h) Each plot should be hariested as soon as it is thoroughly matured, care being taken to avoid losses through shelling before the yield is determined. 
(i) The product of each plot should be threshed by hand and the yield computed with the greatest possible care.

(j) Sort trials should be repeated for at least two or three years before drawing any conclusions as to the relative standing of the sorts tested.

2. Yielding Power:-Decided differences often exist between sorts in yielding power. The correct judgment of a sort as regards yield is an important matter and one which can only be made after careful tests have been conducted for a sufficient number of years, in a manner such as that described above. Many sorts have been discredited through unfair judgment; others have obtained a wide distribution because of conditions which were purely accidental. The enormous influence on crops of such agencies as season, soil, manuring, cultivation and quality of seed used, demands that great care be taken in the testing of sorts lest the results be incorrectly interpreted. In any case only the average results over a number of years can be accepted as a fair expression of the yielding power of a given sort. Comparisons between sorts should, according to experience, be continued for about five years. Since the average farmer can seldom conduct sort trials for this length of time, he should obtain two or three sorts which enjoy the highest reputation at his nearest experimental station, and test these for a year or two at least. This comparison should enable him to make a fairly safe choice.

3. Purity of variety:-The possible advantages of pure sorts over those varieties which contain two or more different strains are worthy of note. In pure sorts all plants require the same conditions for germination and possess the same power of utilizing plant food; they exhibit likewise the same attitude toward soil and climatic conditions and toward disease. The result is that if the soil conditions are uniform, the growth is uniformly even throughout the season and the maturity of all plants will take place practically at the same time. Experiments conducted at different experimental stations go to show that the largest yields are obtainable from seed which is allowed to mature perfectly before cutting. If, therefore, the varien contains a mixture of late and early strains, the best quality of seed cannot be expected. Should harvesting be delayed in order to allow the latest strains to mature, the earlier strains will be "dead ripe" and shelling out before those which mature later are fit to cut. "This may entiil considerable loss.

Pure sorts have another advantage over those which are mixed in that their botanical characters are relatively constant and therefore are more clearly defined and more easily recognized. This facilitates a much better control over seed and enables a more accurate determination to be made in regard to its genumeness. This is an important feature both for the seed dea ler and for the buyer, as well as for the judge at exhibitions. 
Mixed varieties, consisting as they do of a number of distinct strains of varying practical values in regard not only to time of ripening but to yielding power, stiffness of straw and resistance against disease, are likely to give a product of less value than that of pure sorts. These varieties may' however, under certain circumstances, have their advantages. Thus a variety may contain strains which differ from each other chiefly in their attitudes towards different conditions of soil and season. They may be almost identical in appearance, may ripen simultaneously, may possess the same stiffness of straw and the same resistance against disease yet one may thrive best on soils which are lighter, warmer and drier while another may give better results on a heavier, colder and moister soil. Were a variety of such composition sown on a field in which the soil is exceedingly variable, it is conceivable that a better average might be obtained than from an absolutely pure sort which demands more exact conditions. The difficulty of knowing the real nature of the strains which go to make up a mixed variety is such, however, as to render it an unsafe practice to depend upon the possible virtues of a composite race.

4. Quality in a sort is a very inportant character and should be carefully considered when a choice of variety is being made. In wheats very considerable differences exist between different sorts in regard to the quality of flour they produce. In oats the percentage of hull to kernel, which in this case is the common measure of quality, differs to a marked extent in different sorts. In fodder crops the quality of fodder produced by different varieties often exhibits marked differences. Determinations of quality on the basis of general appearances are frequently misleading. Thus, size and plumpness in oats of ten leguiles growers into introducing sorts which actually possess a high per cent. of hull to kernel. A good example is afforded in the Tartar King variety. In corn, ensilage varieties are too often judged on the basis of total volume rather than upon the quality of ensilage produced.

5. Hardiness. - In autumn sown crops, the matter of hardiness or ability to withstand the severe conditions of winter and early spring is an important character. The differences between different autumn wheat sorts, for example, in regard to hardiness is often very considerable, and should be duly observed in making a choice of sorts.

6. Strength of Straw.-In cereals, strength of straw is an important quality. The difference between sorts in this regard is noteworthy and should be taken into consideration when making a choice of sort. On poorer soils the danger from lodging is not so great as on soils in a high state of fertility. In the latter case a stiff strawed sort is of special value.

7. The Ability to withstand or resist Disease is an important quality. Some sorts seem much more susceptible than others to such diseases as rust, smut and blight. 


\section{II.-Concerning Choice of Seed of Chosen Variety.}

1. Vital Energy.- - High vital energy in seed or its power to germinate and develop into a strong, vigorous plant is naturally a matter of the very. first importance. The fact that a seed may be able to germinate and at the same time possess a low degree of vital energy renders it impossible ty means of germination tests to determine its alility to develop into a strong vigorous plant. Germination tests are valuable however in showing the percentage of seed that will germinate under favorable conditions and thus in providing a clue as to its fitness to be used as seed. IVhen the percentage germination is high after the tests have been running for four days in the case of cereals, clovers and many other kinds of seeds, the vital energy is found to be higher than where the per cent. germination in four days is low even though the final count after ten days shows a fairly high per cent. The percentage germination may be easily determined by placing 200 kernels in soil or sand or between sheets of blotting paper and keeping them moist and sufficiently warm for from 8 to 12 days or longer depending upon the kind of seed under consideration. From the number which germinate, the per cent. germination may be quickly reckoned.

In corn, each ear should be tested. This can be done by taking a sample of six kernels from each ear and testing each lot separately. A convenient device for this purpose consists of a box of sand on which is placed a cloth marked off into squares in "checker board" fashion, with each square numbered. The six kernels from ear No. 1 may be placed in square No. 1 and so on until all squares are filled. Another cloth is then placed over the kernels and this in turn covered with sand and the whole kept moist and warm. This arrangement makes it possible to locate and throw out all ears of low vitality.

2. Seed should be plump and large for the sort.-- Each seed consists of a germ or embryo surrounded by reserve food. I nder proper conditions the embryo begins to grow and we have what is pupularly known as germination of the seed. During the early stages of growth the neccsiry plant food is obtained by the young plant from the reserve material contained in the seed for this purpose. Should the conditions of soil or season le unfarorable for early growth and should the seed he undersized or poorly developed, there may not be sufficient food to give the young plant a proper start. Inder such conditions the development of the plant shall he weak from the beginning. Investigation shows that plants, like animals, when stunted at the start cannot attain their normal thrifiness even though subsequent conditions be favoralle. The experimental evidence ohtained from different sources as to the superiority of harge, woll-rleveloped seet is abundant. This evidence may he smmmarized in the follow ing manner:

(a) Plants from poorly developed secds are likely an he lese tigerour and consequently less productive. 
(b) Such plants usually require a longer time to develop and may therefore mature later.

(c) They are more easily weakened or destroyed by insects and diseases.

The size of kernel is of course a relative consideration since some sorts naturally produce smaller kernels than do others. Gold Rain oats, for example, produces a smaller kernel than does Ligowo or White Probestier. The size of kernel by which a sort is characterized has no definite influence upon the value of the sort as such. Certain large kernelled sorts of wheat and oats, for example, are less productive than are other sorts which normally produce a small kernel. The reverse may likewise be the case.

In the case of oats, the "secondary" kernels are usually smaller than are the "primary". They have also a thinner hull. Investigations made by the Association with different varieties has shown there to be approximately seven pounds of hull less in 100 pounds of secondary oats than in the same weight of primary oats. This fact provides two arguments in favor of the severe grading of oats for seeding purposes. In the first place, the removal of the smaller secondary kernels leaves a sample composed of the larger primary kernels which on account of their size are likely to give better results when used for seed. This does not necessarily imply that by sowing better seed a lighter seeding is required per acre. In the second place, the secondary kernels secured as screenings from the fanning mill are more valuable for feeding purposes than are the prinary kernels. In some countries, indeed, a higher price is paid for secondary kernels (screenings) for horse feed than for oats which have not been graded. By the severe grading of oats, therefore, not only is nothing lost but two positive gains may be realized.

Where it is necessary to use seed from a mixed variety containing, as it may, large and small grained strains, it is considered safer practice to use seed of average size rather than the very largest seed. In pure sorts, on the other hand, the largest seed that may be obtained should always be sought for.

3. The seed sown should consist of kernels which are as nearly alike as possible as regards size and development.-Where the seed sown consists of large, small and poorly developed kernels, the resulting crop is likely to consist of a mixture of weak and strong plants. During the growing season the weak individuals lecome more and more suppressed by the stronger so that the stand becomes thinner than it should be. The strong plants, moreover, mature as a rule, before the weaker, the result of which is that not only is the quality inferior but the crop is likewise recluced.

4. Seed should be perfectly matured.-Perfect maturity is indicated by the hardness, color and plumpness of the seed. Seed which is perfectly matured before harvesting has been found to give larger yields when sown than does seed taken from a crop which has been cut on the green side. 
5. Seed should be free from disease.-In oats the most common disease is Loose Smut. This may be prevented in the following manner:-

Use one pint of formalin (formaldehyde) to about forty gallons of water and sprinkle the solution on forty or fifty bushels of oats. Smaller quantities of grain should be treated in similar proportions. The formalin can be obtained at any drug store at forty to fifty cents per pint.

The following method is the one most generally used and is simple and inexpensive:-

During the afternoon or evening before the oats are to be sown, spread the quantity you are going to sow on the barn floor five or six inches deep. Prepare a solution of formalin in the proportions above mentioned ( 1 pint of formalin to 40 gallons of water). With a sprinkling can or broom sprinkle the water evenly over the oats which should then be shovelled over carefully for ten or twclve minutes to insure thorough treatment. They should then be shovelled into a long pile and covered with sacks or blankets to prevent too rapid evaporation of the formalin. The following morning, the oats should again be spread out and shovelled until they are dry enough to sow. Oats treated in this way in the evening can be sown the following day.

Caution.-(a) Oats sown shortly after being treated will not feed so easily in a seeder or grain drill owing to the dampness. Special care should always be taken in regulating the seeder in order that the desired quantity per acre be sown, otherwise there is danger of liaving a thin stand.

(b) Do not leave the piles covered with bags more than fifteen hours as there is danger of injuring the vitality of the seed.

(c) Do not allow the formalin can to remain open, as this liquid is very volatile and evaporates quickly. For the same reason do not prepare the solution until the oats are ready to be treated.

In wheat, Bunt or Stinking Smut (Tilletia foetans) is the most serious pest. This disease may be quite effectively prevented by any one of several methods, of which the Blue-Stone Treatment and Formalin Trea:ment are the two most common.

The Blue-Stone Treatment:-Dissolve one pound of copper sulphate (Blue-Stone) in twenty gallons of soft water. Immerse the grain for about 12 hours, stirring occasionally; then spread out in a thin layer and dry rapidly. Sow as soon as possible.

The purest copper sulphate is sold in the form of crystals. These are readily dissolved in a small quantity of hot water. Nfer removing the grain from the solution some recommend immersing it for five minutes in lime water, made by putting one pound of good lime into ten gallons of water. 
Formalin Treatment:-- Use one pound of Formalin in every forty gallons of water. If the seed was from a crop which was infested with smut, it should be immersed in the solution and stirred thoroughly, after which the smut balls, which rise to the surface, should be skimmed off. The seed should be left in the solution for two hours, after which it should be removed and spread out to dry.

If the seed is from a crop which was not infested with smut, it may he treated much the same as in the case of oats, namely, by sprinkling thoroughly in the pile and covering this with canvas or sacks. After leaving in this condition for ahout two hours, the sacks should be removed and the seed acrated.

Treatment for Barley Smuts

In barley a "Covered Smut" (I'stilago Hordei), resembling somewhat Bunt in wheat, sometimes occurs. For this species the Formalin treatment recommended for wheat is advisecl.

The most common disease of consequence in harley is Loose Smut (I'stilago nurla Jens). This may be prevented by treating the seed as follows:-

Place the barley in cold water for about three hours, after which remove and leave untouched for about ten hours. At the end of this time prepare two barrels of hot water having a temperature of about $125^{\circ} \mathrm{F}$. It is important that exactly this temperature be maintained. Place the barley in a sack having an open mesh and dip first into one barrel and then into the other, repeating this operation about twenty times occupying in all about five minutes. After withdrawing the sack each time, hold it out of the water only long enough to allow the water to run off. By using two barrels as above, the proper temperature is more easily maintained. A small amount of seed should be handled at a time, otherwise the grains on the inside will not receive sufficient treatment. After treating in the above manner, spread the seed out on the floor in a thin layer and allow to dry. This process may be assisted by a frequent shovelling of the grain. The seed should be sown as soon as sufficiently dry.

Farmers living near cheese factories can often arrange to utilize the large metal milk tanks which are not in use in early spring, and have their seed treated for a small fee. The facilities provided at these places for maintaining an even temperature render the above plan a comparatively simple and effective one.

6. Seed should be free from damage of any kind.- Injuries frequently follow neglect to keep seed dry. Where this precaution is ignored moulds frequently (levelop, causing a lowering of the growing power. Care should also be taken in threshing seed in order to avoid breaking the kernel and thereby injuring the germ. It is a dangerous practice to thresh severely 
or by other means "clip" the kernels, a practice which is frequently followed for the purpose of making the grain pack more closely in the measure, thus weighing heavier per bushel. This is especially dangerous in the case of barley which is very brittle and liable to break.

\section{Regarding the Changing of Seed.}

It has been claimed by some that seed should be changed every few years, no matter under what condition it may have been produced. Others claim that seed to be sown on light soils should be secured from a crop produced on heavy soils and vice versa. Others claim that only under the most exceptional conditions should seed be changed. While all of these views cannot be correct in their entirety, yet there is a certain amount of truth in each which is determined entirely by circumstances.

The question is when should a change of seed be made. There is no doubt that considerable loss may sometimes result from using seed from a given crop when such crop is poor or otherwise unsuitable.

Generally speaking, a change of seed should be made only in the following cases:--

(a) When seed of better and more serviceable sorts than those now being used are available. This can only be determined by carefully testing other sorts which seem to promise better than those now being cultivated. In the meantime, the old sort should be continued until absolute proof is obtained as to the relative standing of the new introduction. It may happen that changed conditions on a farm may make a change of sort desirable.

(b) When a sort has become mixed with other sorts.- The desirability of using pure sorts has already been pointed out (See page 11).

(c) When the crop becomes seriously damaged by reason of unfarorable weather or other agencies.-The danger of using seed which is not perfectlydeveloped and which has been harvested badly has already been referred to. It may happen, however, that seed of fair quality may be obtained from a crop which is partially damaged, but in no case should such seed be used until it has been tested for germination and growing energy:

(d) When seed has been damaged by threshing or by defective storing methors.

(e) When suitable machinery is not aidable for cleaning seed properly:From what we have already said regarding the superiority of uniform and plump seed, the necessity of thoroughly cleaning all grain intended for seeding purposes is obvious. All seed should be run through a good fanning mill at least three times. If this cannot be done, it is advisable to procure seed of suitable quality and purity elsewhere. 


\section{Regarding Degeneration in Potatoes, and Change of Seed Tubers.}

The problem of potato improvement by the selection of favorable fluctuations or variations is intimately linked with that of "degeneration." That potatoes degenerate or "run out" naturally is an idea commonly held by the great mass of growers no matter where they may be situated. Many believe that this is a natural phenomenon-something to be expected and something which cannot possibly be avoided. A new variety comes into circulation, remains in the foremost ranks for a few years or until it reaches a period of old age or senility and then gradually declines. Such is the gen . erally accepted idea of the life of a potato sort. That certain varieties do appear to act in this peculiar manner cannot be denied. On the other hand, experience shows that other sorts which have been under cultivation a great many years do not appear to have lost in vigor or productive qualities during this long space of time. A good example is afforded in the Swedish sort known as Dala which is commonly grown in the Province of Delecarlia (Dalarne). This potato is said to have been introduced about 150 years ago, yet is one of the best sorts now grown in that Province.

The degeneration which is often noticed in potatoes is not regarded by our best authorities as due to any natural or inevitable "running out" of the sort, but rather to the effects of certain conditions which weaken the vigor and invite disease. Potatoes seem to reach their highest state of development under cool, moist conditions, seed tubers produced under such conditions usually giving better results than those grown in hotter and drier regions.* Where potato growing is prosecuted in these latter districts, it would seem desirable to obtain seed frequently from districts which allow the maximum development of vigor. Where this practice is not followed, the vigor may gradually become weakened, resulting in a corresponding depreciation in yield and quality. Similar results in any case may follow neglect to discriminate between small, poorly developed tubers and those which are well developed and sound. Too of ten all the good sound tubers are sold or used for cooking while the poor, discarded and in many cases diseased tubers are kept for planting. Where this practice is followed there is bound to be a falling off in productiveness. The evidence at present available goes to show that where suitable sorts are used and where suitable nubers of these sorts are utilized for seeding purposes each year, the standard. of a variety may be maintained indefinitely under all favorable conditions of soil and climate. Since some varieties are not adapted to certain conditions it is quite possible that their power to resist disease may become gradually reduced. This would seem to explain why certain varieties grown in comparison with others and under similar conditions for a number of years seem to be more susceptible to blight and other diseases than do neighboring sorts. Obviously, the first consideration is maintenance of vigor and control of disease and this implies very careful selection of seed tubers, careful cultivation, spraying and rotation of crops.

* See D. 73, Fourth Annual Report, Canadian Seed Growers Association, for confirmatory evidence by Mr. IV. T. Macoun, C. E. Farm, Ottawa, Ontario. 


\section{Principles of Plant Improvement.}

When single plants of the self-fertile class (wheat, oats, barley, peas, etc.) are propagated separately in small isolated cultures (so-called pedigree cultures) they breed relatively true from generation to generation providing, of course, they are not the product of a recent crossing but are constant (homozygous) in character. This fact, together with the discovery of the composite character of many of our old varieties has caused most specialists at breeding stations to adopt a system whereby the constituents of these old varieties may be isolated and tested in large numbers separately. By a process of elimination, based on yielding tests and careful studies of each culture, both in the field and in the laboratory, the number is gradually reduced until only the best remains. Further progress is then usually sought by combining the desirable characters of the best strains by means of hybridization.

While the above system is eminently suited to Experimental Stations, where time and money are specially allowed for such work, ret the old system of mass-selection may still be regarded as the most practicable one Sy'stem of seed selection for the by which the average farmer may annually obtain good seed on his own farm. This system will be outlined in detail later. By means of this method of selection a degree of purity may be maintained in large seed cultures which is scarcely possible in any other way. This in itself is sufficient to justify the application of the system. If applied to crossfertilizing crops such as corn, this method is full of promise of great gains, as in this case it may actually produce a cumulative effect; if applied to varieties of self-fertilizing crops which have become mixed, either through the accidental introduction of foreign sorts or through other causes, it provides a means of effecting improvements by at least separating oul the inferior strains and effecting an inclusion of the best.

Since selection, be it "pecligree" selection or "mass" selection, according to most modern authorities, does not produce anything new but simply separates out that which already exists, its value after a cortain point has been reached would, in the case of self-fertilizing plants, appear negligible. In so far as being able to effect any accumulation of hereditary variations is concerned, this may be quite true. On the other hand, there are certain physiological factors or agencies such as soil. climate, food and moisture supply which play an exceedingly important part in the growing of crops and which merit the utmost attention. These factors cause what are known as "fluctuating" variations, that is variations caused by environment and which, according to most modern breeders, are not hereditary. The selection of farorahle fluctuating variations may not lead therefore, to any improvement in the race as such but there is abundant evidence to show that the superiority of the seed from such variations-from plants which have attained the mest perfect development and maturity-manifests itself in better crops for one generation at least. In other words, modifications produced by murture may 
not be hereditary lut may he re-impressed on each generation by providing the proper cultural conditions.

The seed may be regarded as an unborn plant drawing its nourishment from the mother. If the mother is poorly nourished, the embryonic plantthe seed-is poorly dereloped. This is a simple case of malnutrition. Experience goes to show that such seed always produces plants of inferior development. This principle is exemplified in the runt of the swine litter. Such an individual, as is well known, seldom recovers that which has been withlseld from it during the incubation or pre-natal period.

Importance of continued mass-selec tion.
Importance of high cullural conditions for seed groaing.
While seed from inferior fluctuations-from poorly developed and immature plants may often be quite effectively excluded by the severe screening and grading of the bulk sample, yet it is considered a better and safer practice to select desirable plants in the first place, in order that the said sample may contain as little poor seed as possible. This fact, together with the fact that purity in a variety may be most effectively maintained from year to year by the annual inclusion or selection of a sufficient quantity of typical heads, panicles or pods to sow a small culture or plot the following year as a base of supply, renders the system of mass selection exceedingly useful and one which every farmer should include as a part of his regular system of farm management.

In view of the importance of obtaining seed from plants which are perfectly developed and matured, the aim of the grower should be to provide such physical conditions in both the surface and subsoil of his land as will enable the plant to attain maximum development.

This fact suggests at once the desirability of every farmer setting aside his best patch of land each year as a seed producing centre or plot and that he allow the crop produced thereon to mature perfectly before harvesting. Another practice, and one which every farmer may follow to advantage, is to locate, or mark off, the best patch or patches in his fields before harvesting, and allow these to stand until thoroughly mature. They may then be harvested and threshed separately, the seed being kept apart for the following year's seeding. A still better practice, however, is that followed by members of the Canadian Seed Growers' Association and which is described in detail in the following pages of this publication. 


\section{THE GANADIAN SEED GROWERS' ASSOCIATION AND ITS WORK.}

This Association is an outgrowth of what was known as "The Macdonald Seed Grain Competition," a competition in seed growing which began in 1900 and which continued for three years, extending over the entire Origin and chief aim of Dominion and including, in all, about 1,500 competitors. The object of this competition was to stimulate an interest in the production and sclection of high class seed by providing visible demonstrations as to the practical advantages which may accrue from the use of such seed. At the close of the competition, the Macdonald Robertson Seed Growers' Association was organized with a view to promoting, through organized effort, a continued interest in this question. The name of this Association was changed in 1904 to "The Canadian Seel Crowers' Association," which name it still holds.

The Association seeks to attain its object hy enlisting as memlers, farmers who desire to make a specialty of growing on their own farms, high class seed of one or more kinds of crop under expert direction. In this way is created a base of supply of pure seed of high quality which in turn is multiplied under the Association's inspection and control and made available for seeding purposes to the general farming public.

The officers of the Association consist of a President, three Vice-Presidents, a Secretary-Treasurer, an Executive Council and a Board of Directorconsisting of twenty members. The Directors are elected annually from the different Provinces in Canada so that the work is entirely national in character and far reaching in influence.

The membership consists of Honorary and Active members. Any person of good repute is eligible for membership as an active member providing he conforms to the by-laws and regulations of the Association.

Before being elected an active member in full standing. the A-sociation requires that each applicant make a hand-selection of seed in sufficient quantity to enable him to sow a Hand-selected seed Plot of the required size, the following year. It also requires wherever practicable. that his work be inspected and commended by an officer approved he the Association.

No membership fee is at present required. Applications for admintrice should be addressed to the Secretary, Canadian Seed Growers Association. Canadian Building, Otlazia, Canada.

The work of the Association maty be said to be an cotension of that Department of the Govermment service conducted by the Experimental Farms. The latter institutions coneluct work in original research with field crops, test different varietics obtaned from different parts of the workl 
and endeaior to envolve, through a process of breeding and selection superior strains for use on Canadian farms. They are not, however, in a position to control the multiplication and distribution of these sorts in a large way and to best adrantage among individual farmers. This important work can best be done by a separate and independent organization for obvious reasons. Were all seed of superior strains distributed direct to growers without the exercise of any control over its succeeding progeny, the greater part would quickly lose its identity and eventually be either ruined by lack of proper care in maintaining purity or completely lost. The conservation of all that is good and useful in improved stocks, together with their judicious multiplication and distribution on an extensive scale and under efficient control is therefore one of the main aims of the Association.

In the prosecution of its work the Association closely co-operates with the Seed Branch of the Dominion Department of Agriculture. The District Representatives of the Seed Branch do most of the field and commercial seed inspection. This phase of the work will be referred to later.

Funds.

Although this important public service is executed by a voluntary organization outsicle of the Govermment, yet, on account of the value of such work to the country as a whole, together with the service which it is possible for such an organization to render in preventing the dissipation of improved stocks produced by experts, the necessary funds are obtained annually from the Dominion Government.

\section{General System of Seed Growing adopted by the C.S.G.A.}

The general system of seed growing adopted by members of the Association is briefly as follows:--

Choice of V'ariety.

Having decided upon the crop or crops of which it is proposed to produce seed of special quality each year, the member is urged to choose with great care the variety with which to operate. If he is uncertain as to which variety will clo best on his farm, he is strongly advised to test two or three of the very best known sorts in duplicate or triplicate plots in accordance with the plan submitted on page 10. The great importance of this cannot be over-estimated as no grower can afford to work with an inferior or unsuitable sort.

The desirability of limiting the number of varieties under general cultivation 10 as few as possible is fully recognized by the Association. With this cnd in view, there will henceforth be accepted for registration in the records of the Association only such varieties as are approved by a special committee appointed for this purpose.* This committee consists of the

\footnotetext{
* Sce "Report of the Board of Directors," in the Eighth Annual Renort (1911-12) of the C.S.G.A.
} 
Superintendents of Experimental Stations, the Agronomists and Horticulturists of Agricultural Colleges, the District Representatives of the Dominion Seed Branch, and the Secretary of the Association, who acts as chairman. This arrangement implies that all new varieties must be thoroughly tested and must prove their superiority to the satisfaction of the committee before being recommended for Registration in the records of the Association.

Having decided upon the variety, the next step is to procure a quantity. of so-called "Elite Stock Seed" of that varicty. By the term "Eitie Stock Seed" is meant seed which has been specially selected in accordance with

Production of Elite Stock Seed." definite rules as herebelow stated, and which is regarded by the Executive Council of the Association to be worthy of multiplication and distribution. (See Definition of Terms, p. 48). This seed may often be obtained from another member who has been operating for a number of years and who has a supply of such seed on hand, or it may sometimes be had from an Experimental Station. Where Elite Stock Seed or its immediate progeny can be obtained in the beginning, the work of the new member is rery much simplified, since his future concern will consist chiefly in keeping the sort pure and multiplying it under the inspection and direction of the Association. Seed obtained in this way will be accepted for Registration in the records of the Association from the beginning and will be given a certain standing.

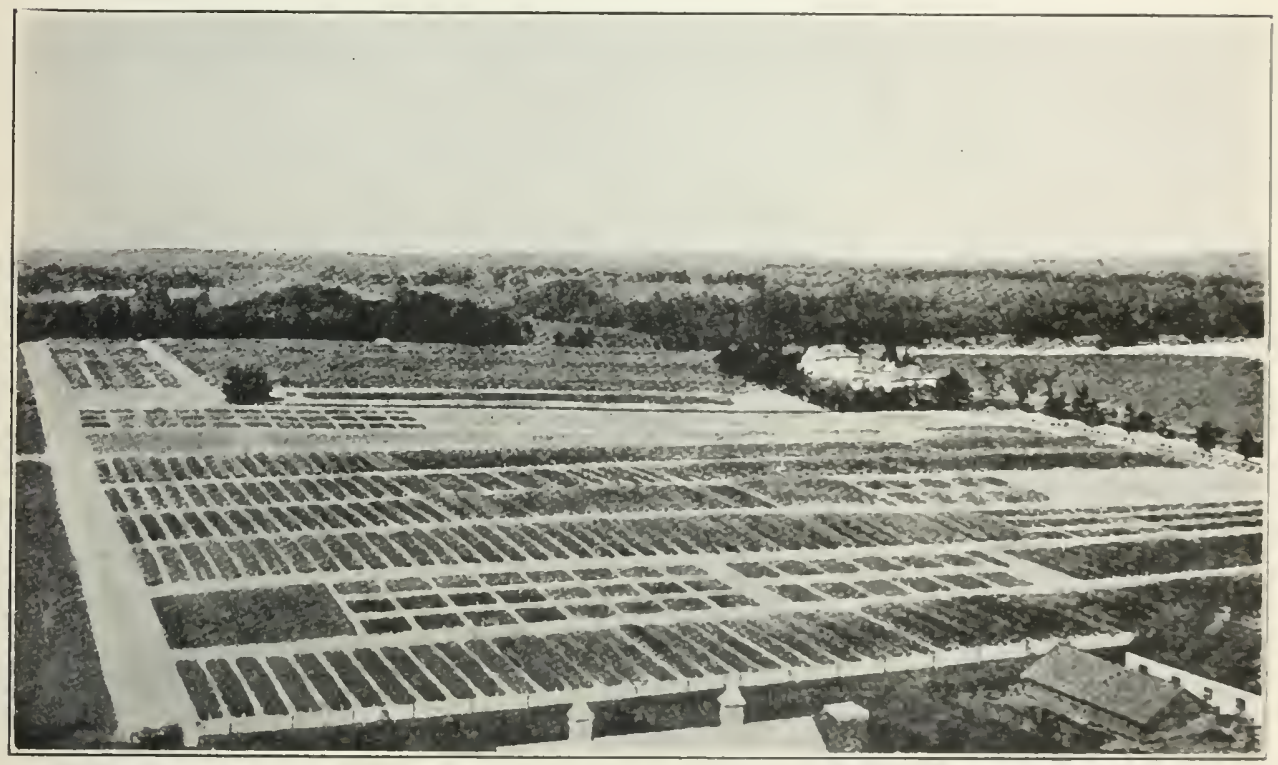

FIG. I.-Experimental and breeding plots at the ()..1.C.. Guelph, Ont.. from which place come many of our best loundation Stocks. 


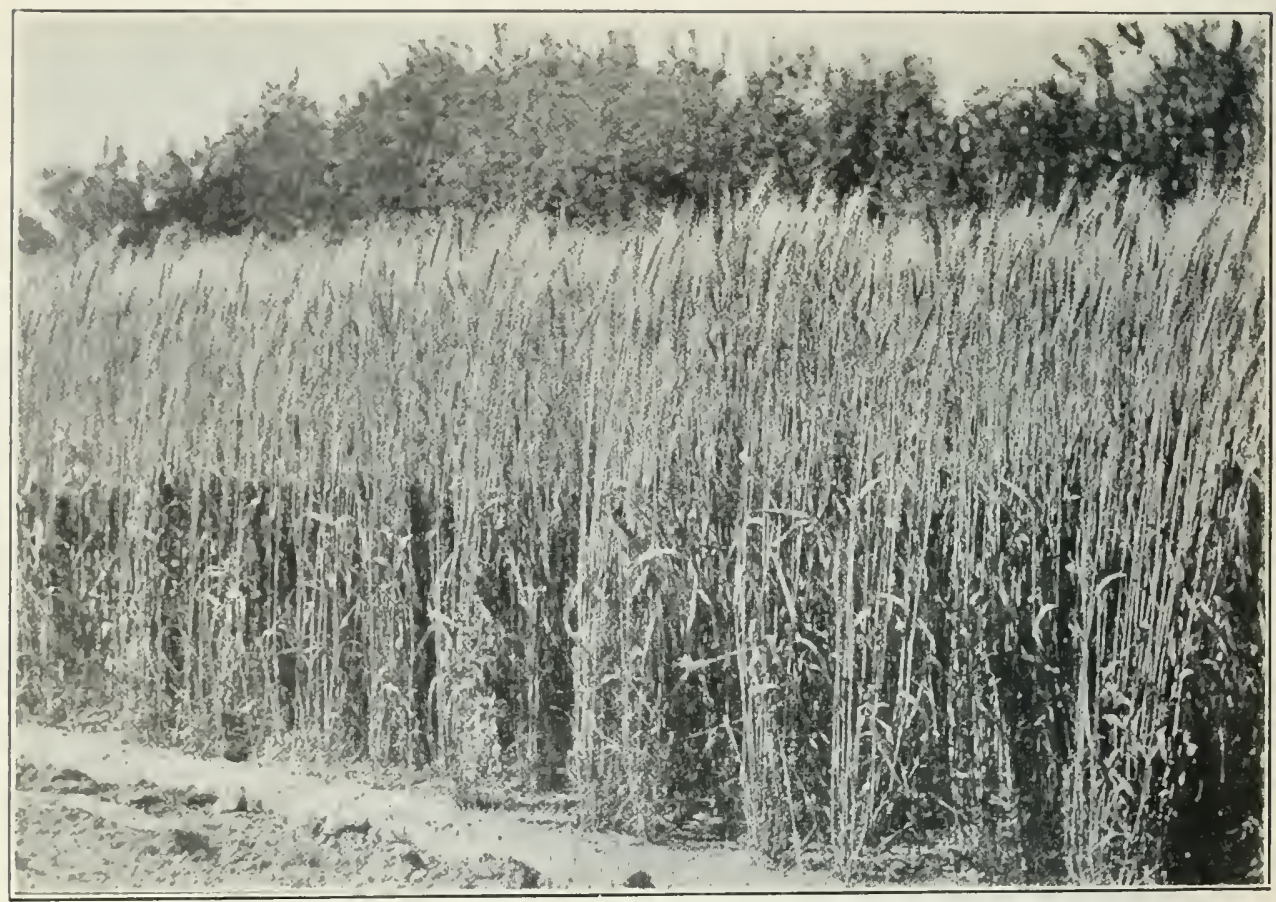

Photo by S. W.

Fig. II.-Special Seed Ilot of Preston IIheat grown hy S. Wheeler, Rosthern, Sask. Stock Seed secured originally from the Central Experimental Farm, Ottawa, Ont.

The special seed plot as a mentis of ohtaining Slock Seed.

Where this seed is not available the grower must produce it himself. This may be accomplished by operating each year a special seed plot of the chosen variety and selecting therefrom a sufficient quantity of typical heads, panicles, ears, pods or tuhers, as the case may he, to give enough seed ("Hand-selected seel") to sow another plot the following year. After three or four years of careful selection there should ordinarily be produced a stock of seed of sufficient purity and quality to entitle it to be ranked as "Elite Siock Seed." This practice assumes the presence of more than one strain within the mother variety and implies the desirability of eliminating all but that or those which promise hest. This is the system of mass-selection before referred to and which is considered specially useful for the practical farmer who seldom has time to undertake the more complicated and exacting methods.

The "hand-selected seed" obtained in the above manner is, in the case of cereals and small seeds, threshed by hand and every precaution is taken to keep it pure.

Anuwal use of Sperial seed plat.

Following the production of Elite Stock Seed the special seed plot must not be abandoned hut must be continued each year as a means of effecting a possible further improvement in certain cases, but more especially as a means of maintaining the purity and quality of the sort and of providing 
a base of supply of high class seed each year. This plot may be controlled in a manner which is quite impossible with the larger field areas and herein lies its main adrantage.

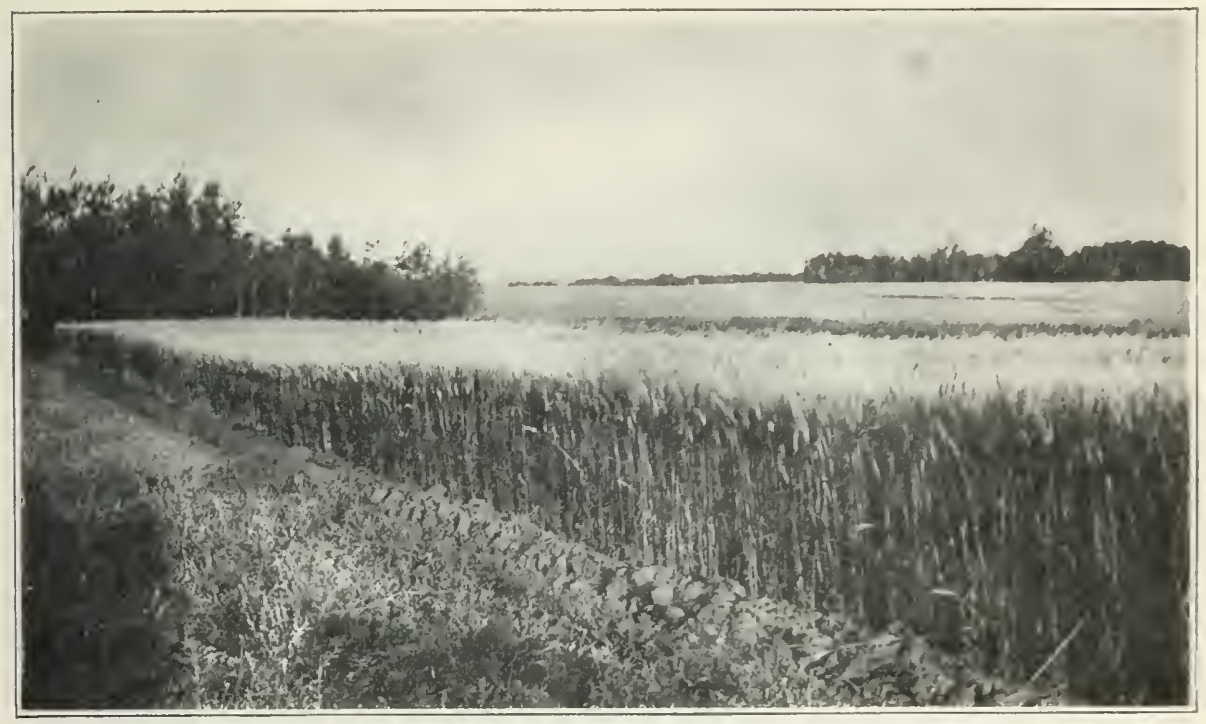

Photo by S. Wheeler.

FIG. II1.- "Hand-Selected Seed Plot" of Wheat in the foreground producing "Elite truck Seed;" "Multiplying Field" in the background producing "Registered Seed."

Since different classes of agricultural plants are considered by the classes of Association, the system of handling the seed plot and of producing Elite A griculturat Stock Seed in the case of each class will be clealt with separately. Four considered. main classes of agricultural plants, as regards methods of reproduction, may be distinguished as follows:-

(a) Those in which the seed is normally produced by the self-fertitization of the flower; e.g. wheat, oats, barley, peas and beans.

(b) Those in which natural cross-fertilization between individual plants is the common rule; c.g. corn, ryc, and most grasise.

(c) Those in which cross fertilization between different indiriduals is obligatory; e.g. Red Clover.

(d) Those which are reproduced in a a'setative way; e.g. the potato. 


\section{Process of producing "Elite Stock Seed" by Selection in the Case of Self-fertilizing Plants, such as Wheat, Oats, Barley and Peas.}

Plants which are self-fertilized, ordinarily breed true and seldom show any hereditary variations by means of which an improvement over the old race may be effected. Thus a strain (pure line) of oats, or wheat or barley developed from a single plant is found to remain practically constant in type from generation to generation providing natural crossing, which even in these crops may occasionally take place, does not occur. Modifications in the character of a plant due to such external factors as a superabundance of food, air, light or moisture are not generally believed to be re. produced, in which case they need not be considered in connection with any system which aims to effect permanent improvements.

In a mixed or composite variety which contains a number of distinct strains, two ways are open for effecting a possible improvement, viz.:-

Pedigree

Selection.

Mass

Selection.

The seed plot.

A mount of seed to select. (a) By selecting a large number of individual plants, propagating these separately in carefully arranged plots and comparing their progeny with a view to isolating, if possible, a pure strain which will excel the mother variety or

(b) By reducing the number of strains in the mixture by a process of continuous mass-selection of heads, panicles or pods from plants which correspond in all essential particulars with a chosen type. In three or four years a relatively pure stock should result from this practice.

The latter system, as already explained, is the more practicable for the average farmer and is therefore recommended to him by this Association.

In the practical application of this system the special seed plot before referred to is employed and the following considerations duly observed:-

1. The seed plot should not be less than one-quarler of an acre in size, and should be fertile, in a state of good cultivation, free from woed seeds and sown at the regular rate of seeding and in the proper place in the rotation.

2. At least thirty or forty pounds of heads, panicles or pods, which are uniform in character should be selected by hand either from the standing crop on this plot when perfectly matured, or from the sheaves before thresh ing. Where practicable, it is advised that this selection be made from the standing plants.

3. The selected heads or panicles should be threshed by hand and the seed carefully cleaned so that a pure uniform sample will be available for sowing the next year's seed plot.

4. The crop on the seed plot should be allowed to mature perfectly lefore harvesting.

5. All impurities should be removed from the above plot before it is harvested. This is a matter which should never be disregarded. 


\section{Process of Procuring "Elite Stock Seed" by Selection in the Case of Corn.}

\section{(Representing plants which naturally cross-fertilize.)}

The degree of purity which may be obtained in the self-fertilizing cereals after two or three years' selection is scarcely to be expected in the case of open-pollinated plants such as corn. Here natural crossing between different strains within the variety as well as between different varieties in adjoining fields is exceedingly common, with the result that true hereditary variations in the form of new combinations of characters are frequently effected. The fittest of these combinations should be conserved by selection. In selecting for specific purposes, such as earliness, nature assists greatly in this process, since the stronger, more perfectly developed strains (combinations) will be revealed by the exigencies of soil and season, as will also those strains which are less suited to survive. A natural acclimitization consequently takes place which may be assisted materially by further elimination and selection by man. This applies naturally to those cases in which the aim is to produce earlier sorts.

The operation of a special corn plot each year offers abundant opportunities, both for effecting actual improvements, as well as facilitating the perpetuation of a relatively pure stock. The following considerations should be closely observed in the operation of this plot:-

1. The plot should be isolated from other varieties in order to preient cross-fertilization. Unless otherwise protected, a distance of approximatel: one-quarter of a mile should be allowed between different sorts, if possible, as the pollen is known to carry this distance in the wind. Where buildings. wood-lots or some other barrier providing a measure of protection intervenes, the above distance is not so neccssary. A field of the same variety. as that planted on the plot, and situated between the latter and another variety, provides a fair measure of protection against inoculation by foreign pollen.

2. The plot should consist of not less than ti'enty rou's with fifty hills per row. Both rows and hills should be at least $3 \frac{1}{2}$ feet apart. Plant each hill with four or five kernels and subsequently thin the foung plants. when two or three inches high, to three plants per hill.

3. Each row in the aboie plot should be planted with corn from a single ear. The ears required to plant this plot should be as nearly alike as pessible in regard to the following particulars, riz.:-shape, length, circumference. covering of butts and tips, shape of kernels, number of row- of kernels on each ear, percentage of corn to cob and color of cobs.

A desirable car of dent corn for Canarla maỵ he described as follews:-

(a) Ciencrally cylindrical in shape with good full middle.

(h) From 9 to $99^{1 \prime \prime}$ long hut not longer. 
(c) From 7 to $\tau_{2}^{1 \prime \prime}$ in circumference.

(d) IVell covered at the tip.

(c) Smooth and well rounderl at the butt.

(f) With not more than 20 rows of kernels.

(g) Kernels broad, flat and wedge-shaped (not shoe-pegged or blocky).

(h) The rows of kernels straight and unbroken.

A desirable ear of flint corn may be described as follows:-

(a) Generally eylindrical in shape.

(b) No limit as to size.

(c) Well covered at tip.

(d) Smooth and even at butt.

(e) Kernels flatly oval.

(f) Rows of kernels straight and unbroken.

It is well to record quite minute details as to the peculiarities or characteristics of each ear planted in the special plot. The recording of such details necessitates a careful examination of each ear and assists in eliminating the danger of planting ears of different types. For this purpose special blank forms are supplied each grower in early spring.

4. Test each ear for vitality. This is important, since a stand as nearly perfect as possible is desirable in order that conditions may be uniform throughout the plot. Where the stand is uneven, certain plants may receive an advantage over others and consequently produce ears which are abnormal. Such ears, when met with, should not be selected for planting on the seed plot of the following year.

5. All undesirable plants in the plot should be detasselled. The tassels, (inale organs) which are situated at the top of the stalk, produce the pollen which falls on the silks of the ear and effects a fertilization of the ovaries. This is followed by the development of the kernel. Where pollen from a strain which produces a large proportion of barren plants, or plants which are inferior in other regards, falls on the silks of a good strain, the resulting kerncts may combine the characters of the good with the bad. In order that only strong, vigorous, productive strains may be concerned in the parentage of seed ears, the tassels slould be removed from all inferior plants in the plot. This should be done as soon as these organs appear and before the pollen has been shed; otherwise this operation will be without value. 


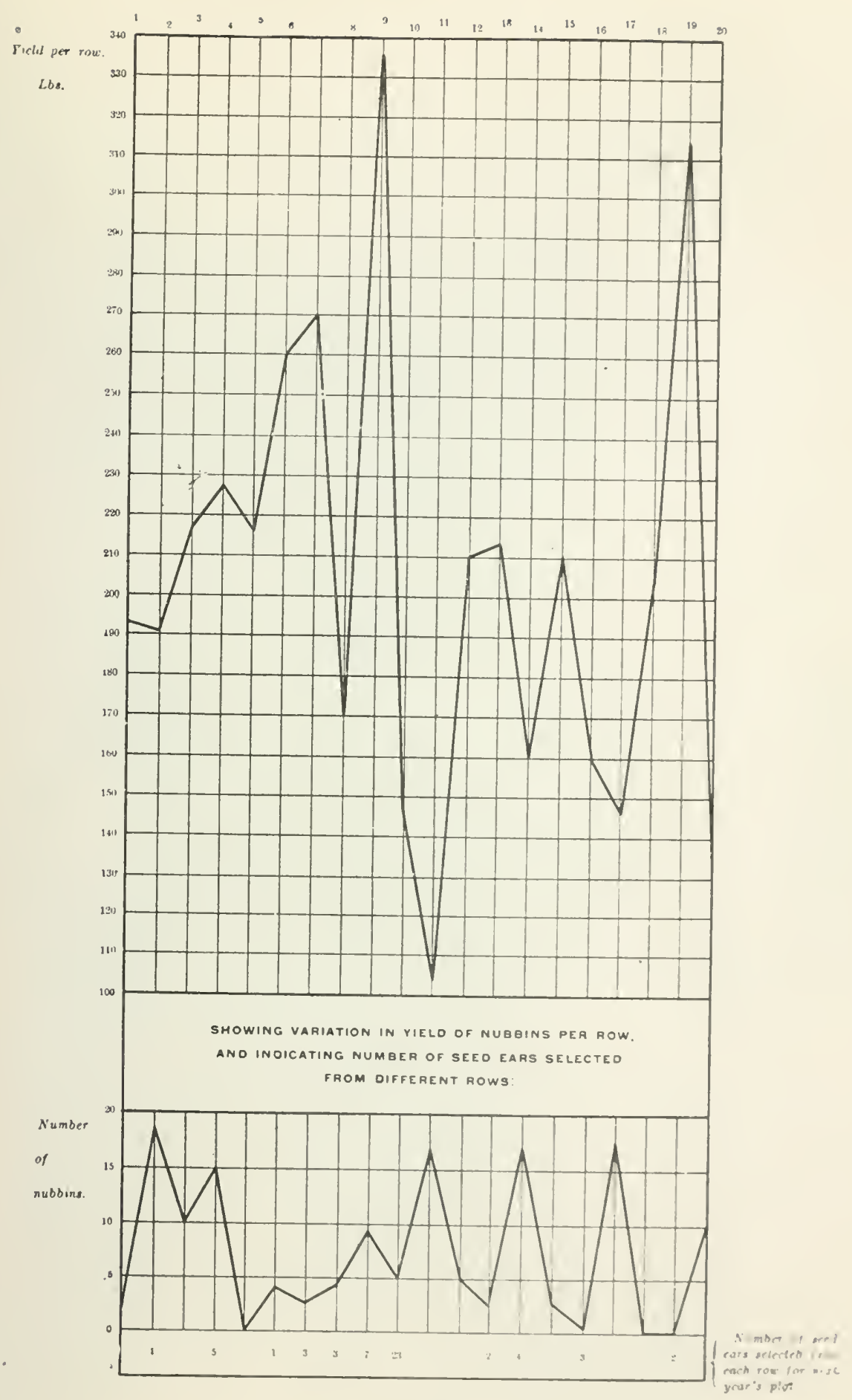

Fic. 11 . 
The stection of seed ears for next year's breeding plot should be made as follow: -

(a) Ascertain and mark from five to ten of the best rows out of the twenty planted. This choice of rows should be based upon such characters as vigor and proluctiveness with special reference to the absence of barren plants and of plants producing nubbins.

(b) Fifty or more of the hest ears, and which approximate most closely the desired type, should be chosen from the best plants in the best rows. The 20 ears actually required to plant next year's plot should finally be chosen, after careful examination, from among the 50 first selected.

(c) These ears should be thoroughly dried before danger of freezing and subsequently stored in a dry, airy place and carefully protected against mice, squirrels and other vermin.

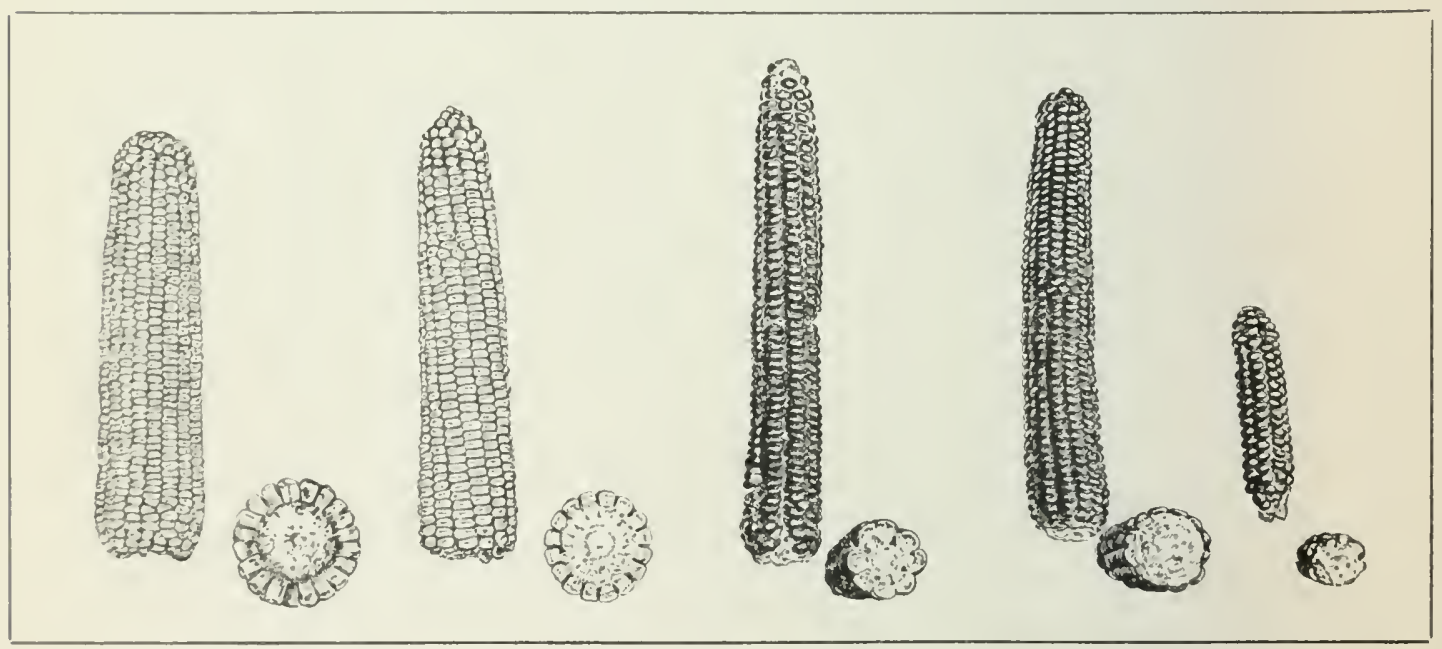

Photo by L. I1. N.

1.IF. 1.-Types of corn from different latitudes in Canada. The further north corn is grown, the shorter and smaller become both ear and kernel. 


\section{Process of Procuring "Elite Stock Seed" ('Tubers) by Selection in the Case of the Potato.}

\section{(Vegetatively Propagated Plants)}

The potato tuber is simply a specialized part of the underground root stem which is stored with starch and covered with buds which are commonly called "eyes". When the tuber or a portion thereof is planted under favorable conditions, the buds begin to grow, the plant food being at first drawn from the tuber itself but eventually from the soil.

While the peculiarities of the mother plant are ordinarily reproduced by means of tubers without any apparent deviation, yet variations occasionally occur. These are believed to arise either as a recult of disease which attacks certain plants and spares others or as a result of some sudden change in the "life" of the tuber itself. Experience seems to show that hoth agencies are active in inducing "tuber variation."

In accordance with the above point of view, the method of potato improvement followed by the Association is based on the principle of contimuous selection of desirable hills and tubers. In the practical application of this principle, a special seed plot is used.

Assuming that the grower has decided upon the variety he wishes to grow and that he has or will have, a plot or field of this variety during the current year, the method of procedure is as follows:-

1. At harvest time, select and keep separate a sufficient number of the most desirable hills to insure there being at least 25 sound hills remaining to plant next year's seed plot. As a rule, ten or fifteen extra hills is ample allowance as substitutes for discards.

2. The tubers from these special hills should be carefully" preserved by themselves over winter, special precaution being taken to avoid roting and sprouting.

3. At planting time, choose an equal number of tubers from the protuct of each of the above 25 mother hills and plant each of these lots hy if eclf in a short row on the plot, the tuhers being planted whole. The number of tubers used to plant each row will be determined hy the hill han ing the fewest number. 
Carman No. 1-Grown near Sussex, N.B.

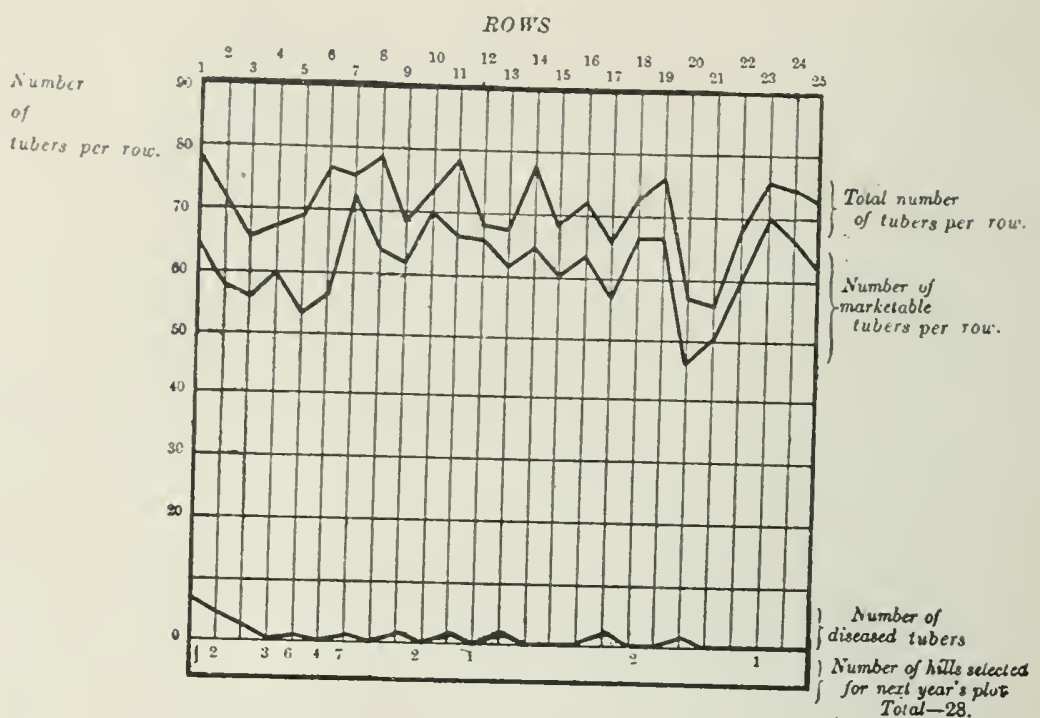

Eary Harvest-Grown near Alhion, P.E.i.

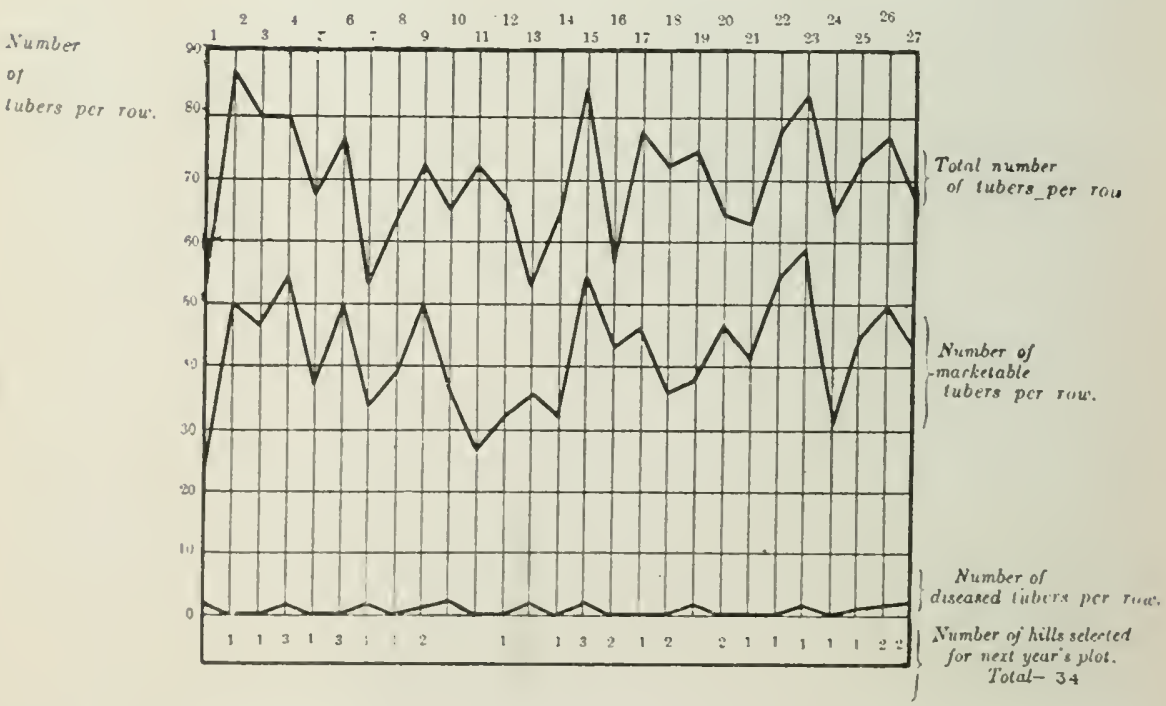

Fig. V1.- Dhatgram - shewing variation in yicld of individual rows of Potatoes grown on Special Seed Plots in 1909. 


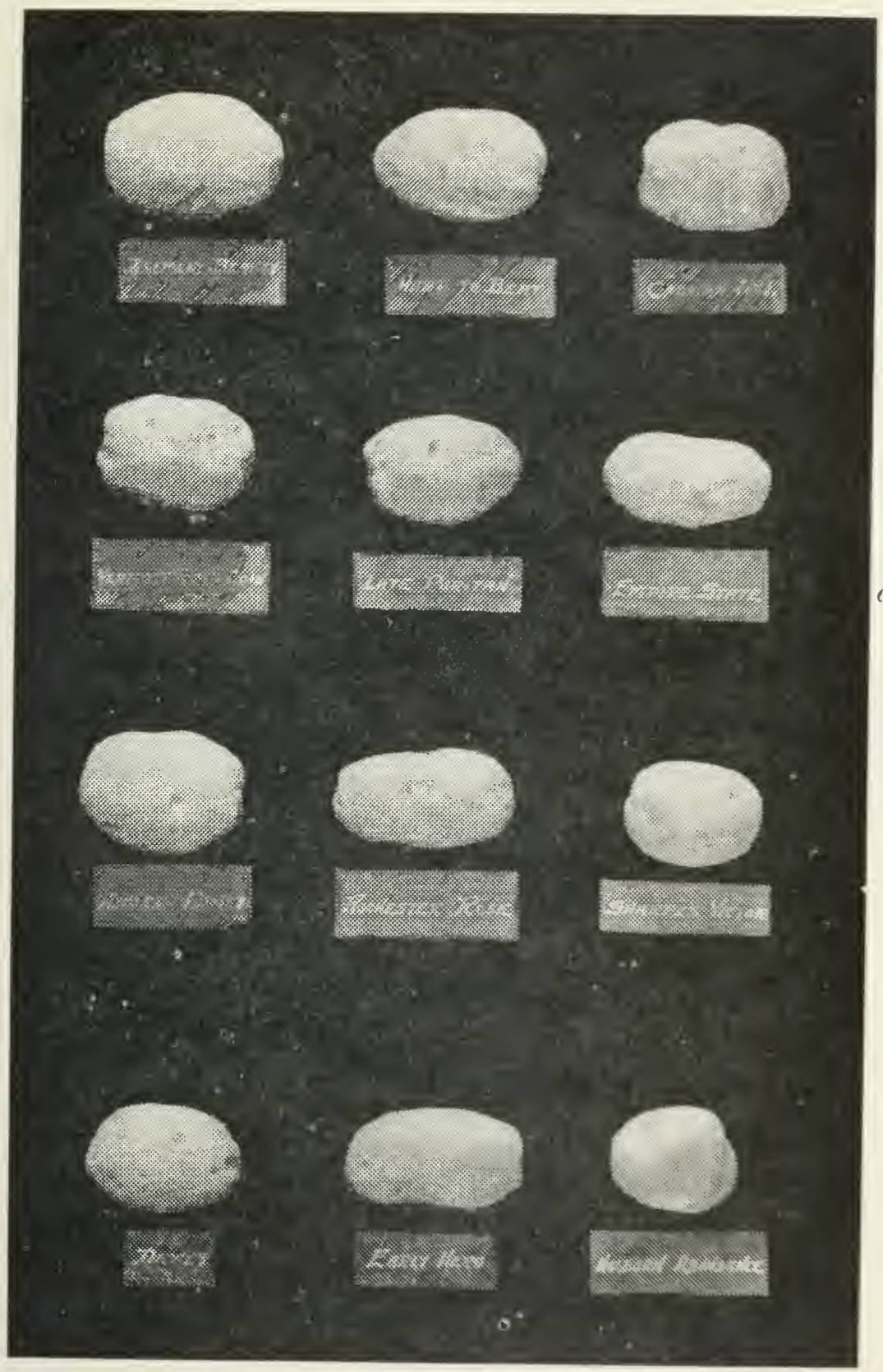

Photo by F. T. Shuse

FiG. VII.-Twelve most productive varieties of Potatoes at the Central Experimental Farm, Ottawa, after five years" test (Money Maker, Carman No. 1 and Dreer's Standard have the best shape. 
4. The selected tubers from each lot may be planted in either of wo ways, viz:--

(a) In parallel rows, making a plot of 25 rows of from 5 to 8 hills each, depending upon the number of tubers available, or

(1) In rontinuous roa's, placed end to end and separated by stakes.

5. All hills and rows in this plot should be at least $30^{\prime \prime}$ apart each way.

Either of the above arrangements permits the grower to determine at harvest time, first the best group or row of hills originating from a single mother hill, and, secondly, the best individual hills within each of these groups. Twenty-five or 30 of these best hills (plus the 10 or 15 extras before referred to) are chosen for next year's plot, while the best of the remaining tubers may be mixed together and used to plant the regular "multiplying ficld."

A seed plot of the size described above (about 1-35 acre) should, under ordinary circumstances and after the 35 or 40 hills have been taken out, produce sufficient seed to plant a "multiplying field" of from $\frac{1}{4}$ to $\frac{1}{2}$ acre where 2 oz. cuts are used and planted $14^{\prime \prime}$ apart, in drills which are $30^{\prime \prime}$ apart. Where a larger multiplying ficld is desired, it is simply necessary to increase the size of the seed plot from which the seed tubers are to be secured.

Vain purpose's sereced by the special secid plot (. Summar) 1 ).

From the above discussion, it will be seen that the special seed plot, in the case of all crops, serves three distinct purposes, viz.:-

(a) It affords a medium through which a relatively pure stock of seed of superior quality may be separated out of a mixed variety.

(1) It provides a practical means of maintaining the purity of all improved stocks from year to year.

(c) It provides the individual grower witl a convenient and reliable supply of "Elite Stock Seed" of superior quality for use each year. This is of value first of all in providing him with seed capable of giving larger and better crops on his own farm and secondly in facilitating the production of seed of a quality which is in demand each year for seeding purposes and for which reasonably remumerative prices are readily offered. 


\section{Regarding the Multiplication of "Elite Stock Seed."}

In the multiplication of "Elite Stock Seed" great care should be exercised in maintaining purity and in insuring a product of superior quality. This requires soil which is fertile, in good physical condition, properly drained, uniform in quality and free from weed seeds. These conditions are imperative where the grower intends to offer seed for sale for sceding purposes. Uniformity of moisture content in the soil throughout the field is especially essential to the production of seed of uniform quality and maturity. Where the surface of the field is uneven, the depressions are almost sure to be moister and thus to cause later ripening. This is especially true in the absence of proper draining. These defects can often be remedied to a considerable extent by levelling. Such work may appear more or less impracticable, but experience has shown it to quickly pay for itself, not only in better quality of crop but in increased yields.*

The practising of a suitable system of crop rotation is a matter of great importance in seed growing. Indeed, the successful seed grower must, of necessity, be one who is skilled in the cultivation of his soil and in arranging his crops in proper sequence. In Eastern Canada, the best quality of seed grain is usually obtained after a hoed crop, a crop which leaves the soil well packed at a depth of four or five inches, yet loose on the surface. Where the soil is light and loose, it is very important that it be thoroughly packed before seeding. In the case of very light soils, it has been found good practice at the Central Experimental Farm, Ottawa, to roll twice before seeding and of ten once after seeding, finishing off after the roller with a light harrow:*

In growing seed grain after summer fallow, as is commonly done in Western Canada, investigations to date seem to indicate that the principle of packing the soil firmly before seeding is quite as applicable as in other cases. The extent to which quality as well as quantity of seed is dependent upon soil conditions indicates that seed improvement and soil improvement must go hand in hand. The aim of the seed grower should therefore be to gradually improve his land. Members of this Association are strongly urged to study with care the question of soil cultivation and crop rotation. Their success as seed growers will depend quite as much, if indeed not more. upon a knowledge of the attributes of "Crood Soil" as it will upon those of "Good Seed."†

The problem of maintaining purity" in the progeny" of "Flite Stock Seed" is an important and more or less arduous one. No matter how careful Mcintuintin: Purity. the grower may he, it is only through eternal vigilance that weed growth

* See address entitied, "Cultural Conditions for seed Growing" by J. H. Grisdale. Eighth Annual Report, C.S.G. Association.

+ Members are referred especially to the following arcicles by Mr. J. 1\}. Gristale. Duector of Fxperimental Farms, Ottawa, in the Second and Eighth Ammal Reports of the Seed crowers" Association respectwely:-

1. "Some Common Principles which Underlie Improvement in Animats and Plants:"

2. "Cultural Conditions for Seed Growing."

Those engaged in potato growing are referred particular!y to Bu!l. 40 (1!)1(1). by M. T. Macot n Ilorticulturist. C.E. Farm, on "The Potato and its Culture." 
and the introduction of foreign varieties may be kept in check. An important precaution which all members are urged to observe is not to grow more than one idriety of wheat or oats, or barley on the same farm. Growers producing oats on a large scale for seecling purposes are also advised not to grow barley on the same farm, and vice versa, providing their system of farming will allow this. With the system of threshing and handling seed which prevails in most parts of Canada, it is very difficult to maintain adequate purity where the above precautions are not taken. Where the itinerant threshing machine is used by members, they are urged to see that it is properly cleaned before entering their premises.

A practice which the Association strongly recommends as a safeguard against the inclusion of impurities in cercals is to "rogue" their fields, that is remore all aberrant individuals by hand, before harvesting. A good plan is to have someone precede the binder and pluck out all foreign varieties which may be found within the width of the swath. This plan obviates the necessity of tramping the crop and is at the same time the easiest and most effective. To do this work thoroughly, it requires about two persons, each of whom may be held responsible for two sides of the field.

Allow the cultures to mature thoroughly.

The cleaning and grading of seed.
The importance of allowing all seed cultures to mature thoroughly before harvesting has already been dealt with so need only be mentioned here. Should a part of the ficld be ripe while another part is still green, the latter should be allowed to stand until thoroughly matured, the former being harvested first.

The proper cleaning and grading of grain in order to produce a clean uniform sample of the best developed seed is one of the most important phases of the seed business. On page 14 of this publication, special reference is made to the double advantage of grading and screening oats so as to reduce the proportion of secondary and poorly developed primary kernels in the sample. It is but little less advantageous to effect similarly close separations in the case of all grains. The smaller and more poorly developed seed can always be used for feeding purposes with immensely greater profit than for seeding. Such a statement has already been sufficiently amplified in the preceding pages of this circular.

In order to separate the Seed from the Feed, a good fanning mill is indispensible. Without such a mill no farmer can hope to become a successful seed grower. This mill has been justly regarded as the most important implement on the farm, yet it is astounding how lightly many farmers regard its use. Indeed, comparatively few farmers seem to have a clear idea as to how it should be used, simply passing their seed through the mill once or twice in a perfunctory sort of way, trusting Providence to make up for any delinquencies on their part. If rightly used, this machine will pay for itself on any farm in one year. I.et us illustrate this: Properly graded seed oats can very casily give 5 bushels per acre more than seed which is not graded. The quality of the crop produced is also likely to be considerably 
better. On an area of ten acres this would mean an increase of 50 bushels, which, at the very moderate price of 5.5 cents per bushel, means a gain of $\$ 27.50$, the average price of a good mill. There are many good fanning mills now on the market and agencies are to be found in most large towns and even villages. We submit herewith a list of some of these:-

The Chatham Mill, manufactured by the Manson Campbell Company, Chatham, Ont.

The Perfection Mill, manufactured by The Templin Manufacturing Company, Fergus, Ont.

The Clipper Mill, manufactured by A. T. Ferrell \& Co., Saginaw, II. S. Mich., U.S.A.

The Tara Mill, manufactured by IV. A. Gerolamy, Tara, Ont.

The Perfection Grain and Seed Separator, manufactured by. The IVestern Manufacturing Co., Ltd., Regina, Sask.

Most fanning mill firms publish excellent illustrated booklets explaining clearly how the different screens should be arranged to remove different impurities as well as all light, shrunken and poorly developed seed from the sample. These booklets are sent free of charge to anyone who applies for them and all growers are strongly urged to secure copies and to study them with care.

Since the size of seed differs in different varieties and in different soils and seasons, it is impossible to lay down any definite rules as to what screens should always be used. The grower must do a little experimenting each year on his own account in order to determine exactly how he may arrange his mill so as to effect the best separation. A half-hour deroted to testing different arrangements and different sieves will be quickly repaid in the quality of work done.

Where the grower has trouble in removing certain impurities such as barley in oats, he may send a small ounce sample to the firm whose mill he is using and have them advise him as to how to overcome the difficulty. The fact that each screen is plainly numbered enables the firm to advise as to which to use. The above service is done free of charge.

For those who use the Chatham Mill, Mr. John Fixter, late of the Central Experimental Farm, Ottawa, has devised a special arrangement of screens for the closer grading of grain. Mr. Fixter's plan of grading oats is substantially as follows: Pass the oats through the mill at least three times. The aim of the first cleaning is to remove lighter kernels, chaff, stems. dirt and other waste matter. The second grading aims to remove still more of the lighter kernels as well as the smaller kernets and weed seeds. The 
third and final grading aims to separate out the remaining smaller kernels and any wheat, barley, tares or other small seeds that may be in the sample. In this case the sieves are so arranged that the best oats pass over the riddle, coming out at the back of the machine instead of in the usual place.

The arrangement of screens for each of the three cleanings is as follows:-

\section{First Cleaning.}

Screen.

No. 6 .

Position in Mill.

No. 12

Next to hopper in upper shoe.

o. 1

Under No. 6 in upper shoe.

Ratchet 1, Pin 1, with wide metal conductorSheet of galvanized iron, about $6^{\prime \prime}$ or $8^{\prime \prime}$ wide, placed on screen under hopper to carry the grain further out on the screen and prevent too much going through.

ํ. 9

In lower shoe, slope to suit.

Open wind blinds at side $20 \%$.

Connecting rod in centre hole of shoe shaker, thus giving a medium shake. Speed good.

\section{Second Cleaning.}

No. 12

In upper shoe with metal conductor under hopper.

o. 16

Ratchet 1, Pin 1.

No. $\mathrm{S}$

In lower shoe.

Open wind blinds $25 \%_{0}^{c}$ or more depending upon the weight of grain. Shake and speed as in first cleaning.

\section{Third Cleaning.}

No. 12

No. 15

No. 11

o. 10

No. $S$ or 9 . .
Under hopper.

With metal conductor as used with No. 12 in second cleaning. U'sing Pin 1, Ratchet 2. In upper shoe.

U'sing Pin 2, Ratchet 4, upper shoe.

Lsing Pin 3, Ratchet 6, upper shoe.

In lower shoe.

Open wind blinds only $10 \%$ or not at all.

Connecting rod in hole of shoe shaker nearest the machine. Speed medium.

In cleaning and grading most varieties of spring wheat, the final separation sliould be through a sieve having a mesh not narrower than $\frac{1}{8} \mathrm{inch}$. Kernets of wheat which pass through a mesh of this width should not ordinarily be used for seeding purposes. 
In cleaning barley for seed, the sieres and riddles used will depend considerably upon the class of seed. In the case of two-rowed barley, the kernels are usually thicker than in the six-rowed sorts, thus permitting the Cleaning barley for seed. use of sieves which have wider meshes. For our common six-rowed varieties, the final separation should be through a sieve having a mesh not narrower than $\frac{1}{8}$ inch.

\section{Regarding the Registration of Seed.}

Seed of approved varieties, which has been grown and handled by members in accordance with the rules of the Association, may be registered in the records of the Association, and may receive certain public recognition in the form of Certificates of Registration. (See Sec. 31 of By-Laws and Regulations). Two classes of certificates are issued. The first is for "Elite Stock Seed" and the second for the succeeding progeny of such seed up to and including the third generation descended therefrom. All seed belonging to the latter category is designated "Registered Seed." (See "Definition of Terms" p. 48). The certificate for "Elite Stock Seed" certifies that the said seed has been produced in accordance with the regulations of the Association and indicates in each case the origin of the seed and, in the case of Stocks produced by mass-selection, the number of years they have been hand-selected. The certificate for "Registered Seed" likewise certifies that the seed has been grown according to regulations and that it has been recorded as "Registered Seed" a certain number of generations descended from "Elite Stock Seed."

While records are kept by the Association of all seed intended for registration, and while full credit is given in the records for all work done by each applicant, yet no Certificates of Registration are issued for any" seed grown by an applicant during his year of probation, i.e. the first year. If the applicant qualifies for membership in the Association and is elected a member at the end of his first year's work, any seed of any kind of crop produced or selected by him during the succeeling vears. and which is otherwise eligible, will then be entitled to receive full recog. nition through Certificates of Registration.

With the exceptions specified below under Section 1I, no Regi-zration 'Tags (Special tags attached to sacks of Registered seed as explained helow) will be issued for any seed unless it be:-

I. (a) Pure as to variety.

(b) Free from any seeds of other cultivited plants:

Certificates of Registration
Shandards ni quality and purity for "Registered seed" adopted by the .1ssicis tion.

(c) Free from any seeds of weeds coming within the meaning of the term "noxious weeds" as applied to the seed Control tet and which are considered by the Executive to be of a dangerous chancter. see helow for list of "noxious weeds.") 


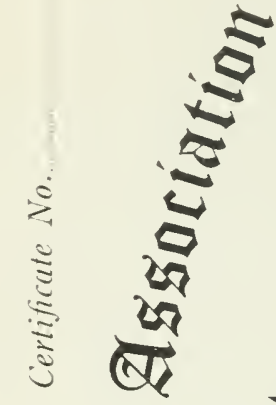

ब

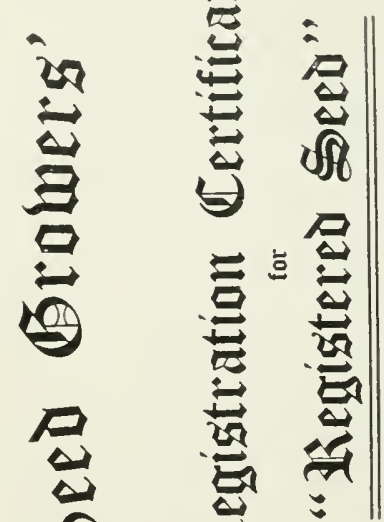

off

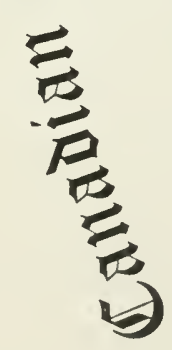

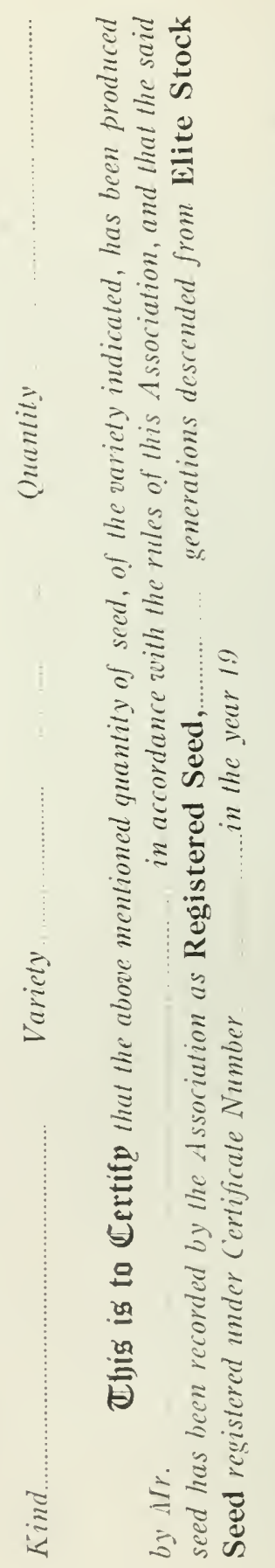

홍

ミ ¿

¿

$\approx$

离

0

$\rightarrow \stackrel{5}{5}$

$\approx 0$

$\approx \approx 0$

¿

ปิ

응

$\approx$

₹

$\stackrel{\Xi}{\equiv}$

इ

$\cong$

등

总密

$\bar{\Xi}$

次

总学

亲

就

5

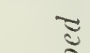

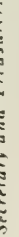

2

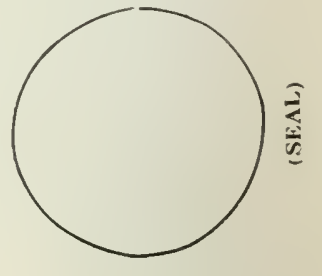


(d) Free from, or containing not more than a total of one seed of other weeds of minor importance, such as wild buckwheat, lamb's quarters, foxtail, etc., per pound of cereals and other seeds of like size and not more than one per ounce of smaller seeds such as flax, grasses and clovers.

(e) Well matured, clean, sound, plump and of good color;

(f) Capable of germinating up to the percentage standard of vitality recognized for good seed of the kind under the Seed Control Act.

II. EXCEPT at the discretion of the Executive Council when Registration Tags may be issued for:-

(a) Seed that will not germinate up to the percentage germination standard for good seed (See below for percentage germination standards), but not below two-thirds of the standard, or

(b) Seed that may contain only a slight trace* of the impurities prohibited by (a), (b) and (d) of Section (I.)

PROVIDED that the seed is of good quality in other particulars and that the percentage germination or the nature and extent of impurities contained, as the case may require, is indicated on the tags attached to the packages or sacks containing the seed.

The weeds coming within the meaning of the term "Noxious IVeeds" as applied to the Seed Control Act are: Wild Oats, Common Darnel, Docks, Purple Cockle, White Cockle, Night-flowering Catchfly, Bladder Campion, Cow Cockle, Stinkweed, False Flax, Ball Mustard, Wild Radish, Wild Mustard, and other Wild Brassica species, Hare's Ear Mustard, Tumbling Mustard, Wild Carrot, Fiєld Bindweed, Dodder in Alfalfa, Blue Bur or Stickweed, Blue IVeed, Ribgrass, Ox-eye Daisy, Canada Thistle, Chicory, Sow Thistles.

The percentage germination standards for good seed, recognized under the Seed Control Act, are:-

Cereal grains, Flax, Indian Corn and Millet

Percentage Germination.

Peas, Beans and Vetches.

Red Clover, Alfalfa, Alsike, White and other Clovers

95 Percentage

90

Timothy, Cocksfoot and Meadow Fescue.................. 90

All other Grasses. . . . . . . . . . . . . . . . . . . . . . . so

Mangel and Beet (160 Sprouts from 100 Balls).............. 90

Turnip, Swedes, Rape, Radish, Cabbage and Cauliflower . . . . . . . 90

Spinach and Carrot......................... so

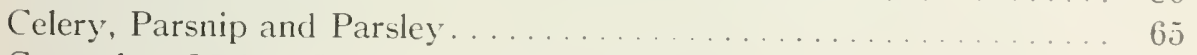

Cucumber, Melon, Squash and other cucurbits. . . . . . . . . . . 90

Onion, Leek and Tomato.......................... 90

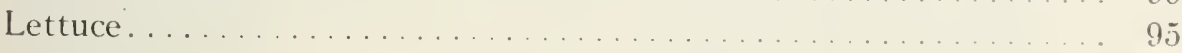

List of Iieeds considered

"Noxious" by Seed Control Act. germination standards.

* The maximum number of seeds allowed under the term " trace" as used in Cl. B., sec. II., is fixed each year by the Executive Council. While the aim of the Association is to give public secog nirion fixed to seed which is absolusely pure, yet conditions during a given year may be such as to justify accepting seed which may contain a trace of less harmful impurities, such as an occasional kernel of barley in oats, etc, 


\section{Regarding the Commercial Handling of "Registered Seed."}

Inspection of seed intended for

Registration.

In the commercial handling of Registered Seed, the Association exercises the greatest possible care in insuring genuineness, purity and quality to the purchaser. This is accomplished in the following ways:-

1. By having the growing crop inspected by an expert.

2. By requiring the grower to submit a representative sample of what he is offering for sale for germination test as well as for analysis for purity.

3. By having the contents of each package or sack which has been sold, inspected by an expert and, where necessary, compared with the official sample, the vitality and purity of which is known.

Sealing of packages or sacks of "Registered Seed" offered for sale.
4. By attaching to each package or sack which has qualified for registration as "Registered Seed" and which has been disposed of, a tag giving the variety name, the number of the Registration Certificate and bearing the Grower's Certificate over his signature as well as the signature of the Inspector confirming the information given on the Tag.

5. By having the above sacks sealed by the Inspector with a metal seal bearing the name of the Association.

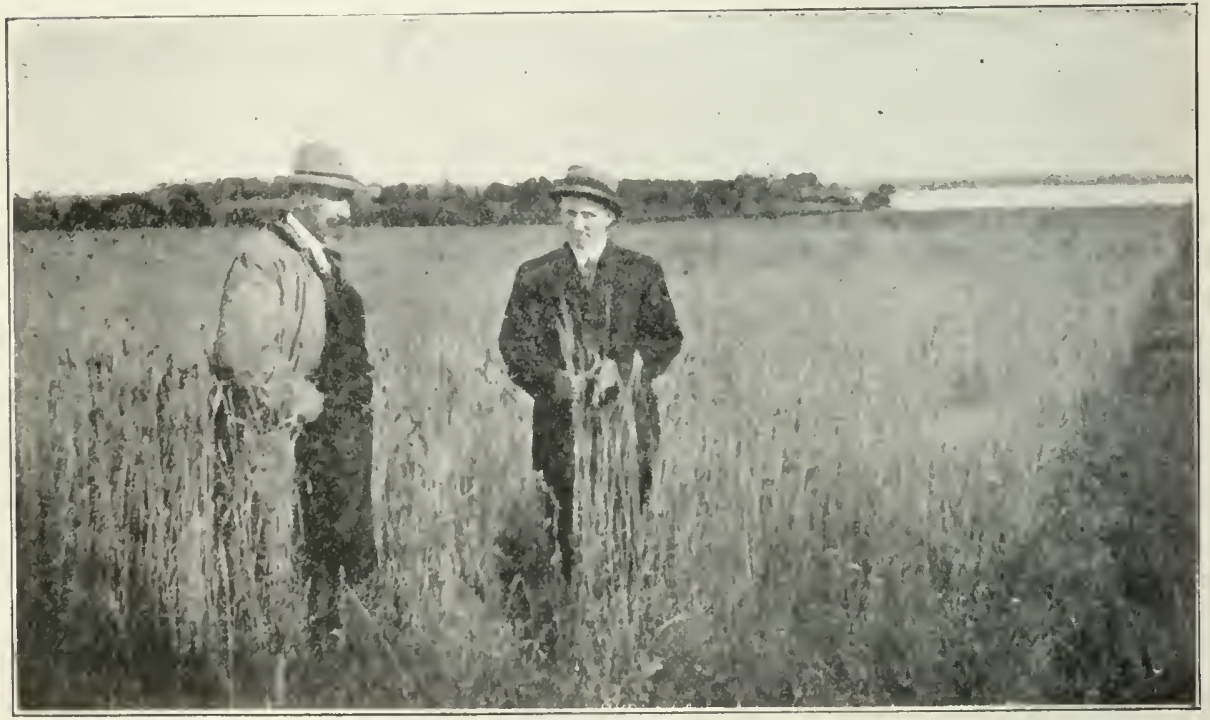

Photo by L. 11. N.

FIG, IX,-Inspector preparing to examine a Multiplying Ficld of Wheat grown by a member in P.E. I, 


\title{
Canadian Seed Growers' Association
}

\author{
REPORT OF FIELD INSPECTION \\ (SPEGIAL FORM FOR WHEAT, OATS AND BARLEY)
}

Name of Member

Address (P.O.)

Prov.

Kind of Grain

Variety

General appearance considering:-

(1) Stand of crop

(2) Vigor and uniformity of growth........

(3) Type of plant considering strength of straw, etc.

Freedom from weeds.

(Names of weeds found in each field:-

Freedom from smut, rust, blight and insects .............................................. (Names of diseases or insects found in each field:-

Freedom from other varieties and other kinds of grain.

(Names of other kinds and varieties of grain found in each field:-

Apparent yield and quality of grain considering:-

(1) Proportion of well filled heads of plump grain of good quality.

(2) State and uniformity of maturity...

Total.

Size of each of the above areas (acres)

Amount of seed likely to be offered for sale from each area

Year in which the seed sown, in the case of each field, originated as the general product of a hand selected Seed Plot: $-\cdots$.

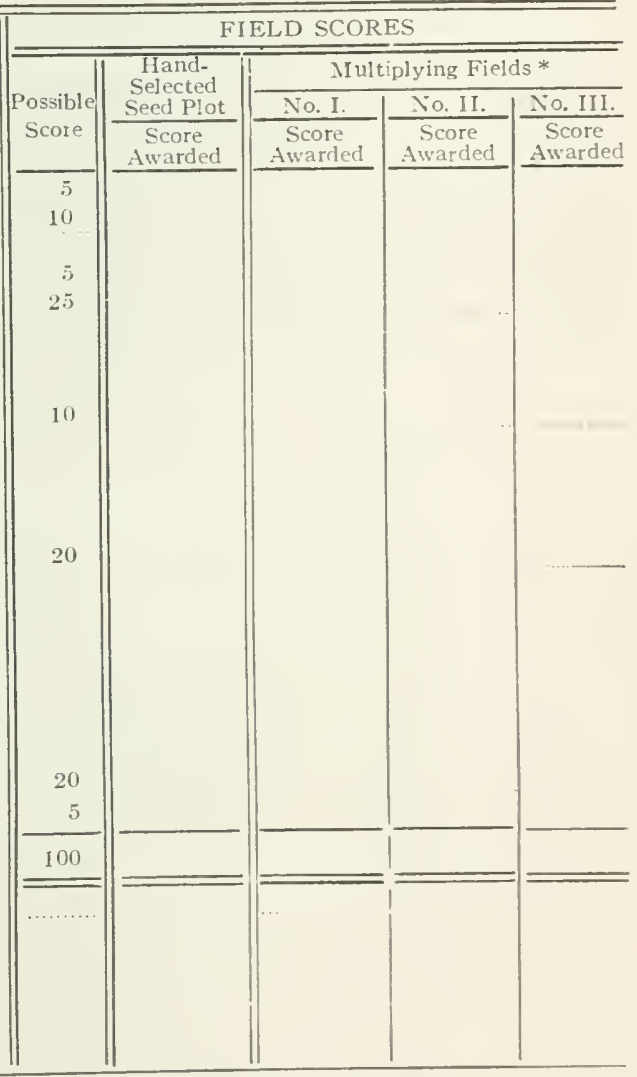

* Where more than three (3) Fields are devoted to the Multiplication of a given Strain a new Sheet should be used, and the additional Fields numbered consecutively from and including No. IV.

Generai Condition of farm

Remarks

Signed:

Date of Inspection:

FIG, X.-Score Card used by Inspector in connection with ficld inspection of cereal grain-. 


\section{$\overbrace{\text { REGISTERED SEED }}$}

Kind

Variety

Quantity in sack

Ibs.

CERTIFICATE NO. E..

GROWLR'S CERTIFICATE.

I hereby certify that the seed contained in this sack was produced by me in the year 191 in accordance with the rules of The Canadian Seed Growers' Association, that it constitutes the generation descended from Elite Stock Seed and that it conforms to the Standards of purity and percentage vitality fixed by the Association for Registered Seed, unless otherwise indicated, as follows: Germination:per cent. below the Standard of $95 \%$.

Minor impurities per lb. of seed:-

Signature of grower

I'. 0 .

Prov

Signature of Inspector confirming the above information and sealing sack...

$$
\text { (tear off here) }
$$

(over)

(NOTE:-Fill in following information before shipping, tear off at above line and forward to Secretary C.S.G. Association)

\section{STATEMENT' OF' 'TRANSFER FOR REGISTERED SELD}

Certificate No. E

Quantity in sack

lbs.

Second owner

Address (1'.O.).

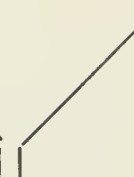

O

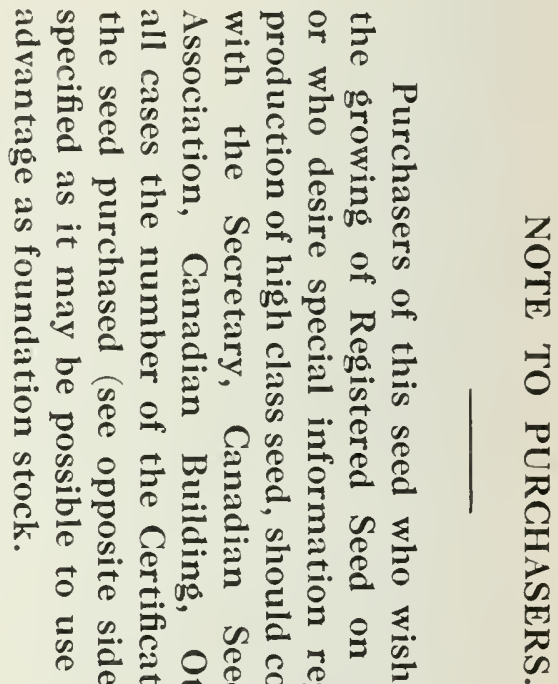

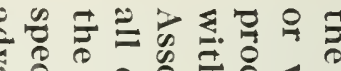

$+\frac{\overrightarrow{0}}{2}$

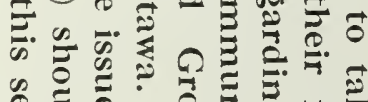

\& $\cong$

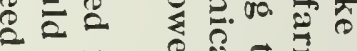

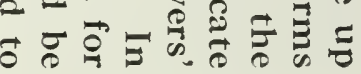

BACK

FIG. X1.-Front and Back views of Registration Tags which are attached by the Association to packages or sacks of Registered Seed before these leave

the premises of the different growers. 


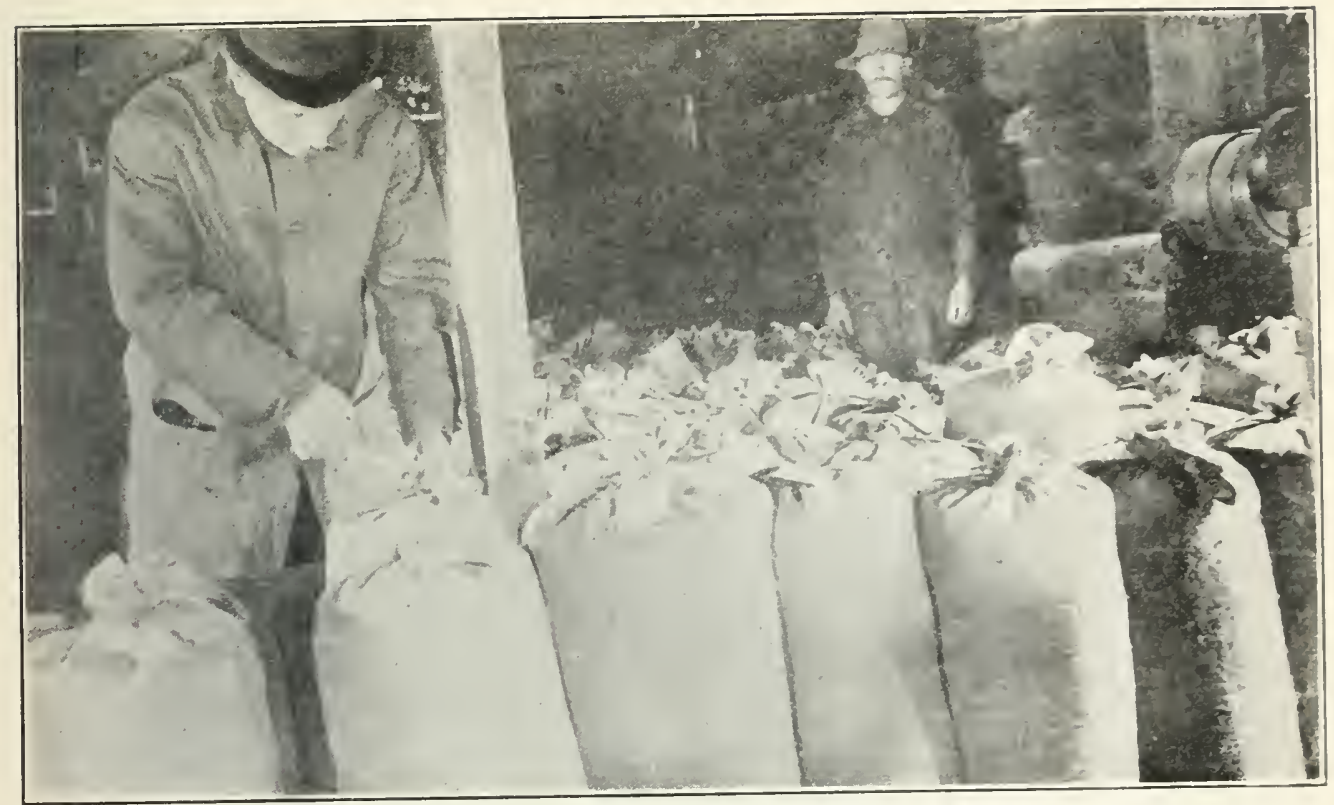

Photo hy L. H. X.

FIG. XIJ,-Officer sealing sacks of Registered Seed Oats on the premises of a member after carefully examining the contents of each sack and comparing with official sample previously examined and tested in the laboratory.

The Registration Tags shown $i_{n}$ Fig. XI. can be clearly seen in the above illustration.

All seed which is grown according to the rules and which has passed the necessary inspection of the Association to date is, if offered for sale, listed in a seed catalogue which is issued by the Association and distributed widely throughout Canada. This catalogue contains, among other things, a list of the names and addresses of all growers who have seed to sell, the price they are asking and the official germination test of each lot. By this arrangement, prospective purchasers are able to locate those having good seed to sell to the mutual benefit of both.

Each grower who has any considerable quantity of seed to sell is also advised to advertise it himself. Special price lists, ad's in agricultural and other papers, correspondence with dealers, ete., are all useful for the above purpose. Excellent advertising facilities are also provided at the Annual Seed Exhibitions which are held by the Association in each district or province in Canada, and which last from two days to one week. Crenwers who are able to attend these exhibitions themselves are often able to place many orders from the sample they are showing. With the control which the Association now has orer "Registered Seed it is reasonably safe to buy from sample in the above manner. 


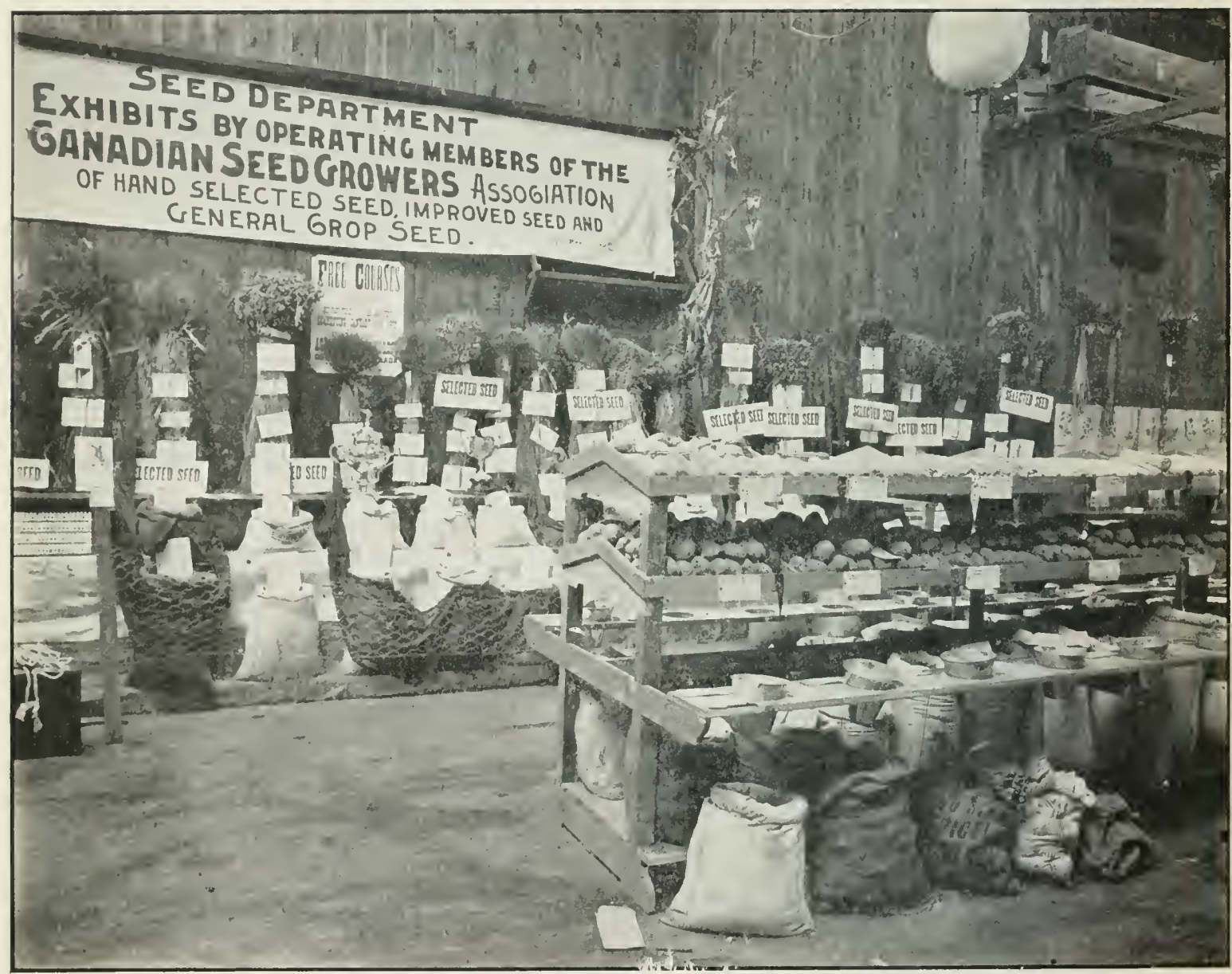

Photo by* E. J. Zavitz

lis,. X11!. - Vart of Exhibit of Selected Seed grown in Ontario and shown at the lVinter Fair, (inclph, Dec.. 1907. Similar exhibitions are held each year in practically all provinces in Canada. 


\section{Advantages of Affiliation with the Association.}

While a grower may apply the above system of seed growing on his farm quite independent of the Association, yet there are certain adrantages associated with an affiliation with this organization which are worthy of consideration. Briefly speaking, the Association is helpful in the following matters:-

1. It enables the member to keep in touch with his fellow worker, and thus to profit by the successes and failures of the latter.

2. Through its publications it keeps the members in touch with the best thought of the times in all matters pertaining to crop raising.

3. It fixes approximate standards of registration for registered seed.

4. It makes a careful study of the results obtained by the different members as well as by professional investigators, and offers direction and guidance accordingly.

5. It keeps the recorts of all work done along these lines hy members. and issues certificates of registration.

6. It assists members in the disposal of their surplus stock of Registered seed.

7. It gives publicity te the work of worthy growers who have succeeded in producing stork of real merit, and which might otherwise semain unrecognized.

8. It provides or obtains prizes for competition with seed produced according to regulations by its members.

9. It gives the grower and his seed public recognition and afforets a valuable means of advertisement.

10. It enables the member to ask a price commensurate with the quality of the goods offered.

11. It facilitates the wider distribution of high-cliss seed. 


\section{DEFINITIONS OF TERMS USED BY THE CANADIAN SEED GROWERS' ASSOCIATION.*}

1. By the term Hand-selected Seed is meant cleaned seed obtained from heads, panicles, pods, ears, or, in the case of potatoes, tubers which are uniform in character and which have been selected by hand from plants which are sound, vigorous and normally developed.

2. By the term IIand-selected Seed Plot is meant a piece of land hearing a crop produced directly from hand-selected seed.

3. By the term Elite Stock Seed is meant:-

(a) The general product of a hand-selected seed plot or other area originating from hand-selected seed of at least three years satisfactory selection and which is considered by the executive to be worthy of distribution, or

(b) A pure stock of seed originating from a single plant, the progeny of which has been proven in plot or field tests (and by other means of examination) to the satisfaction of the executive to be worthy of distribution. This seed must have been propagated exclusively by the originator or under his supervision.

t. By the term Multiplying Field is meant a piece of land devoted to the multiplication of Elite Stock Seed or the progeny thereof up to and including the third generation.

5. By the term Registered Seed is meant the progeny of Elite Stock Seed, up to and including the third generation descended thcrefrom when such progeny has been grown and handled in accordance with the rules of the Association and has been duly accepted for registration.

6. By the term Improved Seed is meant seed originating from handselected seed but which is not yet entitled to public recognition as "Registered Seed."

* The terms here used were adopted by the Association at its Eighth Annual Meeting, all other terms being revoked. 


\section{GANADIAN SEED GROWERS' ASSOCIATION.}

\section{Constitution.}

1. The name of this Association shall be the Canadian Seed Growers' Association; it may have a common seal and alter the same at pleasure; may hold real and personal estate and receive grants and devices of the same; may appoint general and executive officers and define their duties; may receive, reject or suspend members; may establish branch associations and may, from time to time, make rules, regulations and by-laws for the government of the Association and the management of its affairs.

2. The members of this Association may form branch associations for the provinces or districts for the purpose of assisting in carrying the objects of this Association into effect, provided the organization of such branch associations has been authorized by this Association, and their constitution and by-laws have been submitted to and approved by the Board of Directors of this Association.

\section{Objects.}

3. The object of this Association is to advance the interests of seed growers and other farmers by:-

(a) Making regulations respecting the growing, selecting and preserving of seeds of various kinds of farm crops for the guidance of its members;

(b) Causing records to be kept of the history of seeds produced by members.

(c) Fixing standards for seeds that may be eligible for registration.

(d) Publishing information as to standards.

(e) Issuing certificates of registration to nembers by which handselected seed or the product thereof may be distinguished from other seed.

(f) Such other means as may be expedient from time to time.

\section{Officers.}

4. The general officers of the Association shall consist of a president, a secretary, treasurer, and ten directors, which body shall have power to add ten other directors to its number.

5. The president and ten directors shall be elected each vear at the annual meeting of the Assoriation. 
6. Three vicc-presidents shall be elected by and from the completed Board of Directors.

7. The Secretary and Treasurer shall be appointed by the Directors.

8. The officers and directors of the Association shall form the Board of Directors of the Association.

9. The Executive Council of this Association shall consist of the President, the Secretary and Treasurer and five directors to be elected by the Board of Directors.

\section{Membership.}

10. The Association may admit as members any persons resident in Canada who may choose to make seed growing a spccial branch of their farming operations, and who conform to the by-laws and regulations of the Association.

11. The Association may admit as honorary members persons who may be directly or indirectly interested in agriculture in Canada but who may not be producers of secd, and such honorary members shall be eligible to hold office or otherwise enjoy all of the privileges provided for members of the Association.

12. Applicants for membership in this Association may be admitted by rote at any meeting of the Association or of the Executive Council. Any applicant for membership shall become a member of this Association when duly elected by vote of the officers and members or by vote of the Executive Council.

\section{By-Laws and Regulations.*}

\section{Notice of Meetings.}

13. The Executive Council shall cause notices of meetings of the Association to be sent to each of the members at least twenty days prior to the date named for holding the meeting.

14. The President shall cause a notice of any regularly held meeting of the Board of Directors to be sent to each of the members of the said body at least ten days before the date named for holding the meeting.

(b) The President shall cause a notice of any meeting of the Executive Council to be sent to each of the members of the said body at least ten days before the date named for holding the meeting. 


\section{Meetings of the Association.}

15. The Association year will commence on the 1st of April.

16. The Association shall hold at least one meeting each year, the time and place of meeting to be named by the Executive Council.

17. If, from any cause, the Annual Meeting of the Association be not held before the end of the Association year, or due notice thereof be not given, the Executive Council shall cause a special meeting to be called as soon after the end of the Association year as possible, for the purpose of transacting the business of the Annual Meeting, and at such meeting all matters may be dealt with and acted upon as if such meeting were in fact the Annual Meeting of the Association.

18. The usual order of business for the Annual Meeting of the Association shall be:-

The reading and disposal of the minutes of the last meeting.

The reading and disposal of communications.

Report of the Board of Directors.

Reports of the Committees appointed by the Association.

Report of officers.

Unfinished business.

Nomination and election of members of the Association.

Election of the Board of Directors for the ensuing year.

New business.

\section{Meetings of the Board of Directors.}

19. The Board of Directors shall hold meetings at such time and place as may be deemed necessary by the President.

(a) The directors elected at the Annual Meeting shall, at their first meeting thereafter, elect five additional directors, receive the five directors named by the President, and subsequently elect the three vice-president= and Executive Council.

20. The usual order of business for the regular meetings of the Board of Directors shall be:-

The reading and disposal of the minutes of the last meeting.

The reading and disposal of communications. 
Report of the Executive Council.

Report of the Committees appointed by the Board of Directors.

Unfinished business.

New business.

\section{Quorum.}

21. Fifteen members of the Association shall constitute a quorum for the transaction of business at any meeting of the Association of which due notice has been sent to members as heretofore provided.

22. Seven members of the Board of Directors of this Association shall constitute a quorum for the transaction of business at any regular meeting of the Board of Directors.

\section{Powers and Duties of the Board of Directors.}

23. The decisions of the Board of Directors on any matters pertaining to the workings of the Association or to branch associations shall be final.

It shall be the duty of the Board of Directors to -

(a) Direct the operations of the Association.

(b) Make recommendations regarding the revision of the constitution, by-laws and regulations as they may from time to time see fit.

(c) Define the scope of work for this Association and for any branch association that may be formed.

(d) Authorize, whenever they may see fit, the formation of branch associations.

(e) Suspend or expel members who may be found guilty of violating any provisions of the constitution, by-laws or regulations of the Association.

(f) Consider and decide upon any appeals that may be made from any rulings of any person or body connected with this Association or any branch Association.

(g) Consider any appeals or recommendations that may be made by any branch association.

(h) Define the course to be followed in the keeping of records of seed produced by members.

(i) Define the course to be followed in the issuing of certificates of registration to members. 
(j) Define the course to be followed in issuing catalingues or otherwise advertising seed produced by members.

(k) Take such action as may at any time seem to them adrisable in the carrying on of the work of the Association, and in the encouraging of the production and use of high-class seeds of any or all kinds of farm crops.

\section{Executive Council.}

24. It shall be the duty of the Executive Council to transact the business of the Association between meetings of the Association and between meetings of the Board of Directors.

\section{President.}

25. It shall be the duty of the President to preside at all meetings of the Association and of the Board of Directors, and to give the casting vote in case of a tie.

\section{Vice-Presidents.}

26. It shall be the duty of the vice-presidents to aid and assist the President. In the absence of the President, his duties shall devolve on a vice-president.

\section{Secretary.}

27. It shall be the duty of the Secretary to attend all meetings of the Association, the Board of Directors and the Executive Council, and keep correct minutes of the same; to send notices of meetings to members: to issue all publications; to keep records of the seed produced by members and to issuc certificates of registration as directed hy the Board of I)irectors.

\section{Duties of Members.}

28. Each member shall operate annually a hind-selected seed plot in accordance with methods approred by this Assuctation for the purpose of maintaining a constant supply of Elite Stock Seed.

\section{Regarding the Registration of Seed.}

29. This Association shall cause records to be hept of seed of whent, oats, barley, vetches, pealse, beans, maize, millet, llax, seed-potatoes (tuhers and such other crops as the Association maly decide to accept for resistrd- 
tion when the said seed has been grown and handled in accordance with the rules of the Association.

30. All plots and fields producing seed intended for registration, together with the seed obtained from such plots and fields, are subject to the inspection of officers duly authorized by the Association.

31. Certificates of registration may be issued to members for seed of approved varieties grown by them or under their control in accordance with the methods of the Association when such seed has qualified for recognition as "Elite Stock Seed" or as "Registered Seed" as these classes of seed are defined by the Association. (See Definition of Terms.)

32. When certificates of registration for which application has been made by any member are withheld, the Secretary of the Association shall issue a statement setting forth the reasons therefor, which statement shall be sent to the said member by registered mail within ten days after the receipt of his application for the said certificates.

33. The Executive Council shall cause blank forms to be issued in duplicate at an opportune time each year to members and applicants who shall fill them out as fully as possible with the information asked for and attach their signatures thereto, thereby certifying their correctness. One of these forms shall be returned to the Secretary-Treasurer of the Association and the other may be kept by the member for future reference.

\section{Inspection.}

34. Members will at all times endeavor to assist the general officers or any person or persons whom the Executive Council or the President may appoint to enquire into or inspect the operations of nembers in the growing, selecting, preserving or disposing of any seed intended for registration or for which certificates of registration are issued.

\section{Head Office.}

35. The head office of the Association shall be in the City of Ottawa, in the Province of Ontario.

\section{Auditors.}

36. Two auditors shall be appointed to examine the accounts of the Association, one of whom shall be appointed by the Department of Agriculture and the other by the Board of Directors. 


\section{Classified List of Selected Articles and Publications which deal in a practical or semi-scientific manner with the Work of Plant Improvement, etc.}

\section{General.}

Addresses by the President of the C.S.G.A., Dr. Jas. IV. Roberston, at the annual meetings for 1905-12 inclusive. See C.S.G.A. Reports for the years indicated.

Addresses by Hon. Sydney Fisher at the annual meetings for 1905-08 inclusive, also for 1910. See C.S.G.A. Reports for the years indicated.

Papers by the District Representatives of the Dominion Seed Branch presented at each annual meeting. See Annual Reports.

"Scope of work of the Canadian Seed Growers' Association" by Mr. G. H. Clark, Seed Commissioner, Ottawa. See 2nd Annual Report of the C.S.G.Association, page 44.

"Some common principles which underlie improvement in animals and plants," by J. H. Grisdale, B. Agr., Ottawa, 2nd Annual Report of the C.S.G.A., page 92 .

"The seedsman and the C.S.G.A." by S. E. Briggs, Toronto, See tth Annual Report of the C.S.G.A., page 96.

"Methods of giving publicity to the proceedings and achievements of the Canadian Seed Growers' Association" by II'm. Thompson, London, Ontario. See 2nd Annual Report of the C.S.G.A., page 100.

Address, Hon. WV. R. Motherwell, Minister of Agriculture, Regina. See 3rd Annual Report of the C.S.G.A., page 51.

"The commercial value of good seed" bỹ John Mooney, Regina, Sask. See 6th Annual Report of the C.S.G.A., page 111.

"The educationai value of a hand-selected seed plot for boys and girls" by IV. L. Ramsay; Bladworth, Sask. See 7 th Annual Report of C.S.C.A.. page 67 .

"The commercial value of the work of the Canadian Seed Growers" Association" by Geo. H. Bradshaw, Morden, Man. See 7 th Annual Report of the C.S.G.A., page 69 .

Address, by the Hon. Martin Burrell, Minister of Agriculture. Ottawa. See 8th Annual Report of the C.S.G.A. 
Address, by Prof. C. C. James, Toronto, Ont. See 8th Annual Report of the C.S.G.A.

"Vocational Agricultural Education for Boys and Girls" by Mr. Rufus Stimson, Special Agent for Agricultural Education, Boston, Mlass. See 8th Annual Report of the C.S.G.A.

The annual reports of the American Breeders' Association, Sec., IV. M. Hays, Department of Agriculture, Washington, D.C., IT.S.A. Membership, including annual rejorts, $\$ 2.00$ per annum.

Annual Reports of the Central and Branch Experimental Farms, Ottawa, Ont.

†Annual Reports of the Agricultural Colleges at Guelph, Ont., Truro, N.S., St. Annes, Que. and Winnipeg, Man.

Addresses, Hon. W. R. Motherwell, Minister of Agriculture, Regina, Sask. See 4th Annual Report of the C.S.G.A., page 46.

"The Canadian Seed Growers' Association and the Farmer" by Leon Gerin, Coaticook, Que. See 4 th Annual Report of the C.S.G.A., page 87.

"Conditions which effect the vitality and vital energy of seeds" by George Michaud, Assistant Seed Analyst, Ottawa. See 5th Annual Report of the C.S.G.A., page 63 .

Addresses, Mr. Peter Mclienzie, ex-chairman Standing Committee, on Agriculture and Colonization. See 5th Annual Report of the C.S.G.A., page 56.

"The seed plot as an educator," by Mr. J. W. Gibson, Ottawa. See 5 th Annual Report of the C.S.G.A., page 96.

"Some essentials for success in seed growing" by J. R. Oastler, Minister's Island, N.B. See 5th Annual Report, page 102.

"Cleanings from field work in the inspection of seed plots of fellow members," by Donald Innes, Tobique River, N.B. See 5 th Annual Report of the C.S.G.A., page 105.

Address ly Prof. M. J. Black, Agricultural College, Winnipeg, Man. See 6th Annual Report of the C.S.G.A.,"page 86.

Address by Theodore Ross, ('harlottetown, P.E.I. See 6th Annual Report of the C.S.G.A., page 87 . 


\section{Seed Selection.}

"Some results in horticulture from the selection of seeds," by Mr. George Robertson, St. Catharines, Ont. Sec 3rd Annual Report of the C.S.G.A., page 84 .

"Some observations during several years of Seed selection," by Robert MacKay, Millsville, N.S. See 6th Anmual Report of the C.S.C.A., page $\$ 8$.

"Some results from seed selection" by James Marchlank. New Annan. P.E.I. See 6th Annual Report of the C.S.C..A., page 8?.

"Does it pay to operate a special seed plot?" by Richard Creed, Albion, P.E.I. See 6th Annual Report of the C.S.Cr.A., page 70 .

"A means of increasing Agricultural production" by E. D. Eddy, Sced Branch, Ottawa. See 6th Annual Report of the C.S.G.A., page 91.

"The choice of foundation stock and its importance" by Chester Nicholson, Mount Forest, Ont. See 6th Annual Report of the C.S.C.A.. page 96 .

"Evidence of improvement in farm crops by sclection," ly - Prof. C. A. Zavitz, O.A.C., Cruelph. See 2nd Annual Report, page 70 .

"What can the farmer do to improve the yield and quality of his grain," by H. Snyder, St. Anthony Park. See 2nd Annual Report of the C.S.C..... page 77 .

"The special seed plot vs. the general fickd as a source of good seced by W. A. A. Rowe, Neepawa, Man. See sth Annual Report of the C.S.C.A. page 108 .

"Some results oldained from the caroful selection of seeds," by: :-

(a) Geo. Dow, Gillert Plains, Min. 5th Annual Report, page 10!.

(b) T. Turnlull, Manitou, Man. Sth Annual Report, page 111.

"The scope open for the production of highly hred seed in Manitobat,"

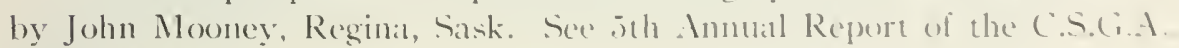
page 112.

"The value of careful seed sclection in maintaining the standard of oun crops," by A. Cooper, Treesbink, Minn. See dith Annual Report of the C.S.C.A., page I01. 
"Plant breeding on the farm," by Seager Wheeler, Rosthern, Man. See 6th Annual Report of the C.S.G.A., page 107.

"Nine years experience in seed selection in Saskatchewan," by F. J. Dash, Hillesden, Sask. See 6th Annual Report of the C.S.G.A., page 109.

"How I discovered and propagated an early strain of Red Fyfe wheat," by Geo. L. Smith, Saskatoon, Sask. See 6th Annual Report, page 110.

"Seed selection and the farmer," by Harry R. Brown, Wallace Bay, N.S. See 6 th Annual Report of the C.S.G.A., page 47.

"Some essential features to be observed in the hand-selection of wheat," by John Mooney, Regina, Sask. See 6th Annual Report of the C.S.G.A.. page 66 .

"Some essential features to be observed in the hand-selection of oats," by George Dow, Gilbert Plains, Man. See 6th Annual Report of the C.S. G.A., page 72 .

"Results obtained from hand-selected seed," by J. L. Henry, Beaver, Man. See 6 th Annual Report of the C.S.G.A., page 79.

"The education and value of a seed plot," by Prof. E. S. Archibald, Truro, N.S. See 7 th Annual Report of the C.S.G.A., page 45.

\section{Re Wheat, Oats and Barley.}

*"Wheat growing in the Canadian West," by Hon. IV. R. Motherwell, Regina, Sask. See 3rd Annual Report of the C.S.G.A., page 59.

"Quality in Wheat," Bull. 57 (51 pages), by Dr. C. E. Saunders and Prof. F. T. Shutt, Dominion Experimental Farms, Ottawa.

"The quality of wheat as influenced by certain soil conditions," by Prof. F. T. Shutt, Chemist, C. E. Farm, Ottawa. See 4th Annual Report of the C.S.G.A., page 52 .

"Observations on the breadmaking qualities of flour made from different varieties of Ontario Fall wheats," by Prof. R. Harcourt, O.C.C., Guelph, Ont. See 4 th Annual Report of the C.S.G.A., page 69.

"The influence of environment on the composition of wheat," by Prof. F. T. Shutt, C. E. Farm, Ottawa. See 6th Annual Report of the C.S.G.A., page 69 . 
"Ten years experience in the growing of Spring wheat in Glengarry Co., Ont." by Robert Mackay, Maxville. See 6th Annual Report of the C.S.G.A., page 97 .

* "Our common barleys and the field open for their improvement in Canada," by Mr. A. P. McVannel, Perth, Ont. See 5th Annual Report of the C.S.G.A., page 86 .

"Grades of wheat," Bull. 60, 21 pages, by Dr. C. E. Saunders and Prof. F. T. Shutt, Dominion Experimental Farms, Ottawa, 1908.

\section{Corn.}

"Corn breeding in the corn belt," by Prof. L. S. Klinck, St. Annes. See 2nd Annual Report of the C.S.G.A., page 56.

* "Methods of storing seed corn," by Prof. L. S. Klinck, St. Annes. See 3rd Annual Report of the C.S.G.A., page 91.

* "Improvement of corn in Canada," by Prof. L. S. Klinck, See 5th Annual Report of the C.S.G.A., page 76.

"Some results obtained in the work of corn improvement and the demand for high class seed corn," by L. D. Hankinson, Grovesend, Ont. See 6th Annual Report of the C.S.G.A., page 92.

"Seven years' experience in selecting corn to meet the climatic conditions of Manitoba," by E. R. James, Rosser, Man. See 7th Annual Report of the C.S.G.A., page 74 .

†Annual Reports, Ontario Corn Growers' Association, Dept. of Agriculture, Toronto.

†Corn breeding in Minnesota,-Bull. 107; Agricultural Experiment Station, St. Anthony Park, Minn., 1908.

Selecting and preparing seed corn,-Bull. 77, Iowa State College, Ames, Iowa, 1904.

"Growing and using corn for ensilage,"--Bull. 65 (16 pages), by J. H. Grisdale, B. Agr., Dominion Experimental Farms, Ottawa, 1910.

\section{Potatoes.}

*"The improvement of the potato," by IV. T. Macoun, C. E. Farm. Ottawa. See 3rd Annual Report of the C.S.G.A., page 77. 
*"The selection of seed potatoes," hy Harry Brown, Wallace Bay, N.S See 5 th Annual Report of the C.S.C.A., page 103.

"Some experiences in crop raising with special reference to the potato," by M. H. Taylor, St. Ciles, Que. See 6 th Annual Report of the C.S.G A., page 63.

"Some results obtained in the improvement of the potato," by Alfred Hutchinson, Mount Forest, Ont. See 6th Annual Report of the C.S.G.A., page 96 .

"Potato breeding in Manitola and some results obtained," by Harols Orchard, Lintrathen, Ont. See 6th Annual Report of the C.S.G.A., page 103

"The potato and its cultures,"-Bulletin 49, Dec, 1910, by IV. T. Macoun, C. E. Farm, Ottawa.

†"Potato growing in Ontario," 1906 Report Farmers' Institutes for Ontario, Department of Agriculture, Toronto, Ont.

†"The potato"-(Book), by Samuel Fraser, Cornell University, Orange Judd Co., N.Y.,-1905.

f"A study of the factors influencing the improvement of the potato," Bulletin No. 127, by Edward M. East, Urbana, I11., 1908.

\section{Field Roots.}

"Selection of seed of field roots and regetable crops in Canada," by Otto Herold, Naterloo, Ont. See 6th Annual Report of the C.S.G.A., page 72 .

"The growing of turnip seed in the Maritime Provinces," by Richard creed, Albion, P.E.I. See 7 th Annual Report of the C.C.S.A., page 49.

\section{Seed Supply, Distribution and Control.}

"Iriekl crops at the Experimental Farm and the distribution of seed so (s)tained," by 1)r. William Saunders of the (. E. Farm, ()ttawa. See 2nd Annual Report of the C.S.G.A., page 81 .

* "How best to encomrage the dissemination of high class seed," by IV. I. Smith, Toronto, Ont. See 3rd Annual Report of the ('.S.G.A., page 92.

"Some problems in seed control," by Creo. H. Clark, Seed Commissioner, Ottawa. See 4th Annual Report of the C.S.G.A., page"85. 
"The distribution of improved seed stocks in Europe," by L. H. Newman, Sec.-Treas. of the C.S.G.A., Ottawa. See 7 th Annual Report of the C.S.G.A., page 100 .

"The distribution of seed produced at Experimental Farms," by C. E. Saunders, of the Central Experimental Farm, Ottawa. See 8th Annual Report of the C.S.G.A.

\section{Insects and Plant Diseases, etc.}

"The action of certain smut preventives on the vitality of wheat," by Prof. F. T. Shutt, Ottawa. See 2nd Annual Report of the C.S.G.A., page 47, also 3rd Annual Report, page 69.

"Insects and fungous enemies of cereal crops and their treatment," by Prof. IV. Lochhead, McDonald College, Que. See 2nd Annual Report of the C.S.G.A., page 47.

"Address," by the late Dr. James Fletcher, C. E. Farm, Ottawa. See 2nd Annual Report of the C.S.G.A., page 103.

"The effect of exposure on solutions of formaldehyde." See th Annual Report of the C.S.G.A., page 50 .

"The treatment of grain for smut," by William Lewis, of I Junsford, ()nt. See 7 th Annual Report of the C.S.G.A., page 5t.

"Insects injurious to grain, fodder corn, root crops and regetables," Bulletin 52, by Dr. Jas. Fletcher, Dominion Experimental Farms, ()trawa, Ont., 1905.

\section{Soils, Fertilizers, the Effects of Culture, etc.}

*"'The relationship between soil conditions and crop improvement," by Prof. R. Harcourt, O.A.C., Guelph, Ont. See 3ra Annual Report of the C.S. C.A., page 55 .

*"Some effects in varieties of cereal crops arising from different conditions of growth," by J. Buchanan, (.A.C., Guelph, Ont. See 3̈rd Anmual Report of the C.S.G.A., page 74 .

"Some soil problems for the grower of improved seed," by J. H. Grisdale, (. E. Farm, Ottawa. See 4 th Annual Report of the C.A.C.A., page y.2.

"Soil cultivation and crop improvement," by 11 . H. Moore, Scotch Lake, N.B. See 4 th Annual Report of the ('.S.C.A., page 96. 


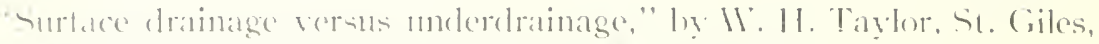

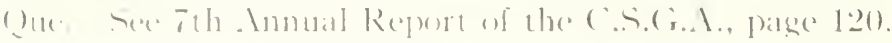

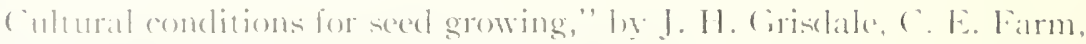

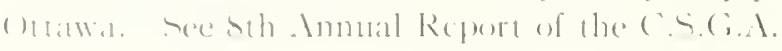

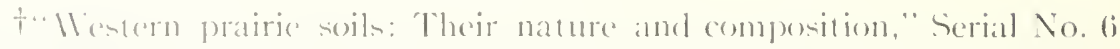

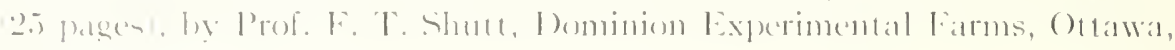
$1 ! 111$.

†"Preparing land for grain crops in Saskatchewan," P'amphlet No. 3,

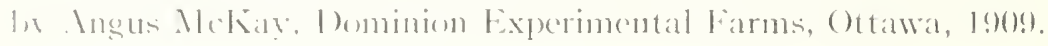

\section{Weeds.}

"The plater of the Canadian Seed Crowers' Association in the campaign

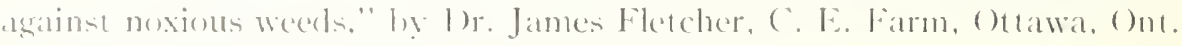

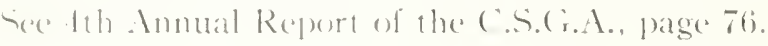

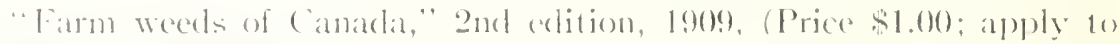
King': l'rinter, (ttatwa).

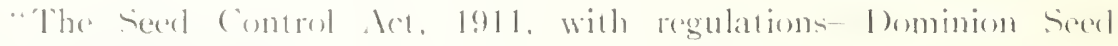
Branch, ()tawal, ()nt.

"Report of the heed Commistoner, 1905) 11 lominion Seed Branch, ()tatwat. (1)nt.

"Mild oats and false wikl oats, their nature and distinetive charaeters,"

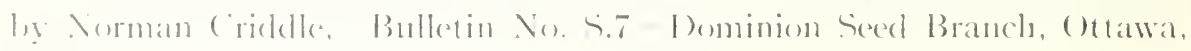
19112 


\section{Selected List of Articles and Publications which deal with the Science of Plant Improvement and Development.}

"Pedigree or grade breeding," loy J. H. Webber, Washington, I).( See 2nd Annual Report of the C.S.G.A., page 61.

"The science of plant breeding," by Dr. J. H. Mebher, Mashington, D.C. See 2 nd Annual Report of the C.S.G.A., page 79.

"Individuality in plants," by Prof. L. S. Klinck, Macdonald college, Que. See 4th Annual Report of the C.S.G.A., page 78.

"The work of plant improsement at home and abroad," by l'rof C.A Zavitz, O.A.C., Guelph, Ont. See 4th Annual Report of the C.S.C.A. page 42.

"The problem of breeding disease-resistant plants,-"Prol. M". Loch. head, Macdonald College, Que. See 4 th Annual Report of the C.S.G.A.. page 64 .

*"The production of improved varieties of cereals," loy I)r. ( . E. Saunders, C. E. Farm, Ottawa. See ith Annual Report of the C.S.(i.A., page 81 .

* "The improrement of farm crops by the selection of individual plants," by Prof. C. A. Zavitz, (iuelph, (Ont. See jth Annual Report of the C.S.C.A. page 85 .

*"How plants feed," hy l'rol. M. Lochhead, Macdonald (ollege, Oue See 5th Annual Report of the ('S.G.A., page 91.

" "Some of the factors which influence the productive capality" of seed," by (icorge Bradshaw, Morden, Man. See jth Annual Report of the C.S.C.A.A. page 106 .

"Hereditary in plants and its learing on agricultural problems," by Prof. ('. A. Zavitz, Cruclph, Ont. See 6 th Annual Report of the C.S.G.A. page 49 .

"Hybriclizing the Ciacliolus," hy H. II. Ciroli, Simcoe, ()me. See bth Annual Report of the ('.S.(i.t., page 52.

"Seed selection as practined in Europe with wheat, outs and harley," by (i. H. Clark, Seed Commissioner, ()ttawa. See bth Anmul Report of the C.S.C.A., page S1.

Discussion hy Dr. C. E. Siunders, C. E. Farm, Ottawa. See buh . Anmual Report of the ('s.ci.A., page st. 
"The importance of choosing suitable varieties as foundation stock," by Ira Rodd, North Milton, Ont. See 6th Annual Report of the C.S.G.A., page SS.

"Plant breeding in Scandinavia," by L. H. Newman, Sec.-Treas. of the C.S.G.A., Ottawa.

"The improvement of fodder plants by selection," by Dr. M. O. Malte, Seed Branch, Ottawa. See 7 th Annual Report of the C.S.G.A., page 100.

"The improvement of cereal grains at Macdonald College," by Prof. L. S. Klinck, of Macdonald College. See 8th Annual Report of the C.S.G.A.

†"The relation of certain biological principles to plant breeding,"Bulletin No. 158, Nov., 1907, by E. M. East, Ph. D., New Haven, Conn., U.S.A.

†'Mendel's Principles of Heredity" (Book), by Prof. W. Bateson, late Professor of Biology, Cambridge University, Eng. Cambridge University Press, 1909. Price \$3.00.

†"Mendelism" (Book), by R. C. Punnett, Professor of Biology, Unirersity of Cambridge, Eng. The Macmillan Company, N.Y., 1911. Price $\$ 1.25$.

Note:-Those publications marked with an asterisk $\left(^{*}\right)$ are not available for general distribution; others may be had on application. All except those marked with a dagger $(\dagger)$ are printed both in French and English. 


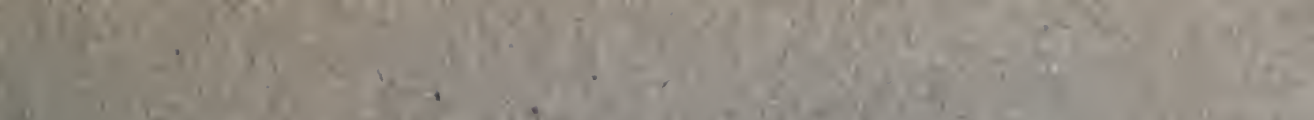

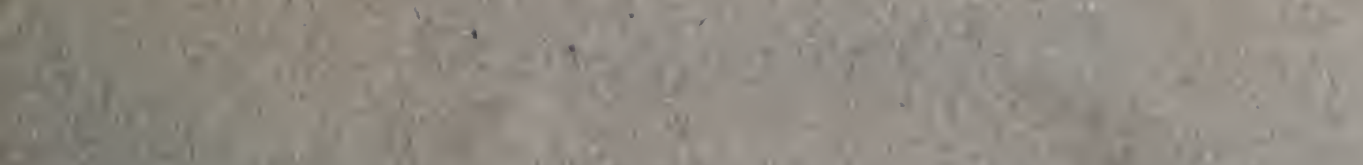

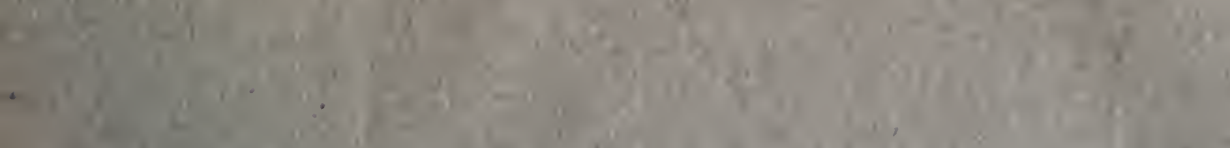

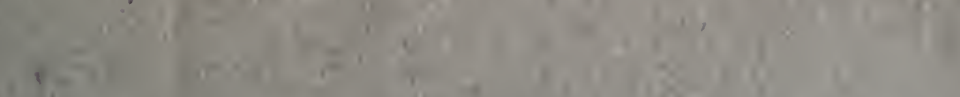

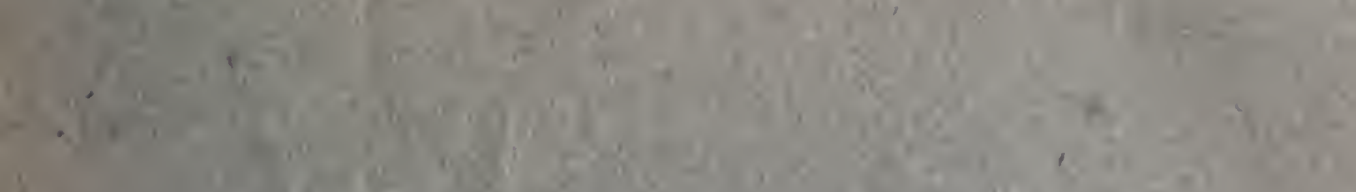

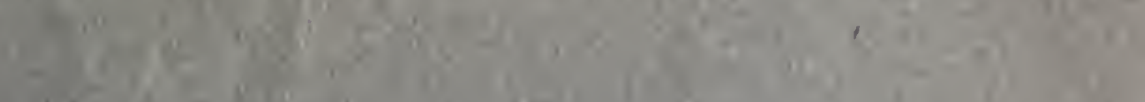

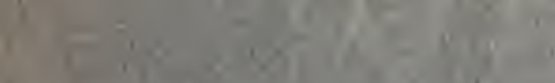

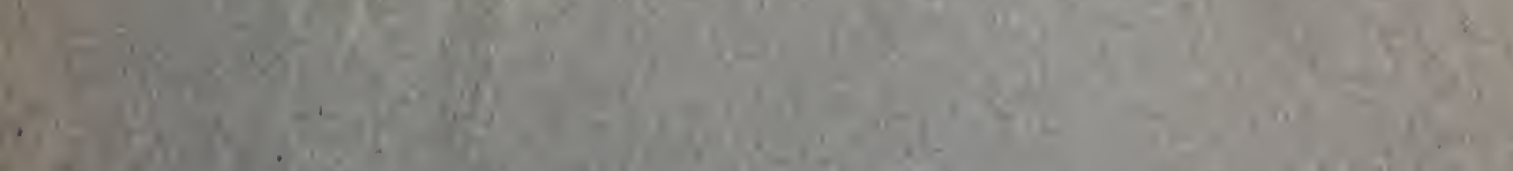

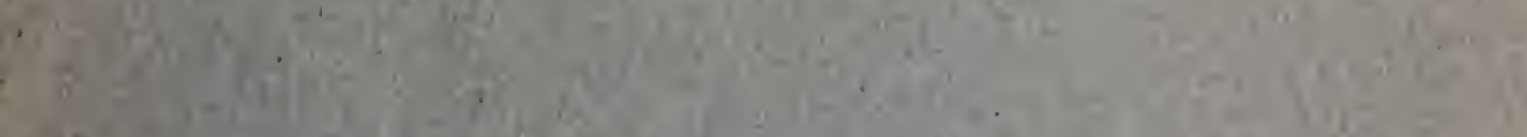
.

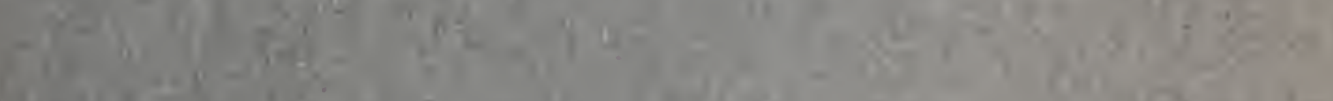

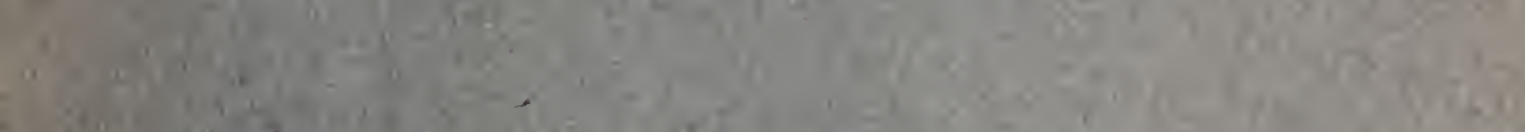

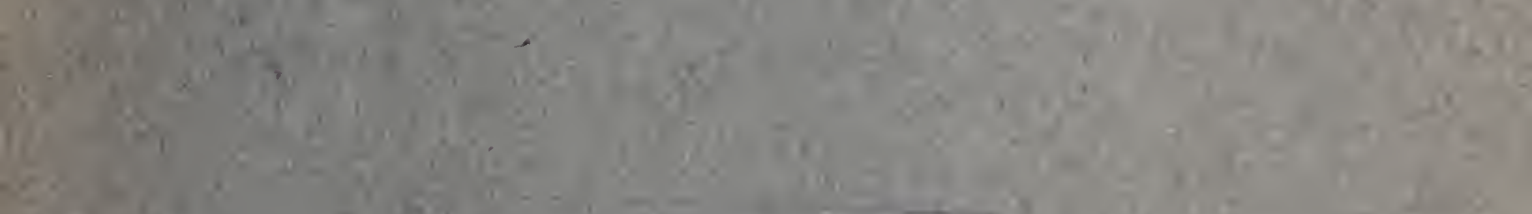

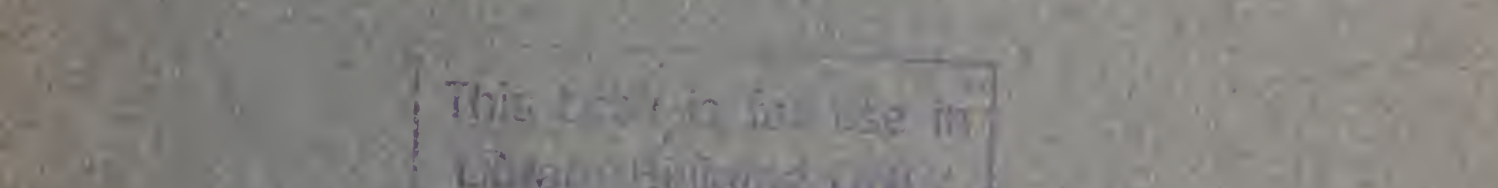

\section{9:} Lidabonglastios unc: taxisis

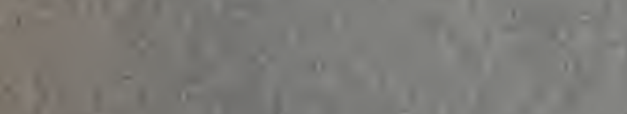

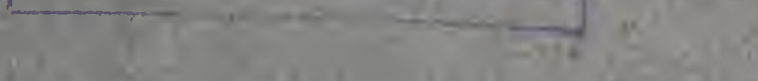

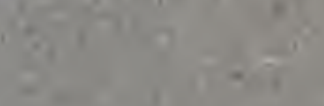

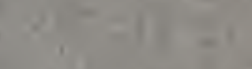

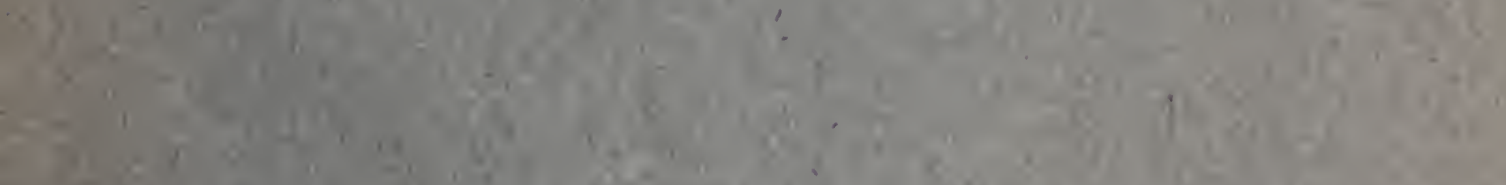

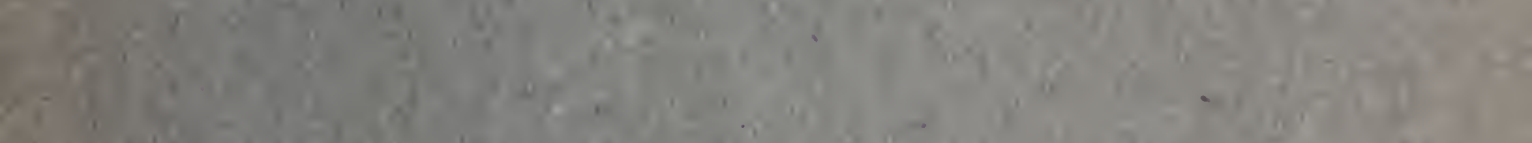

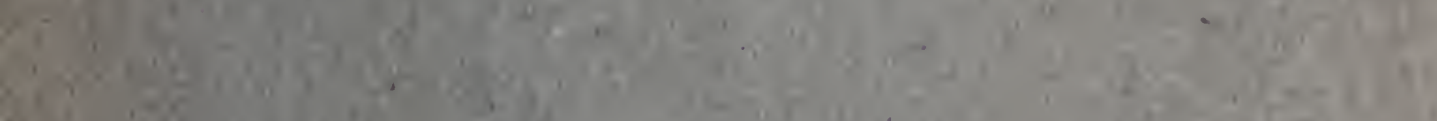

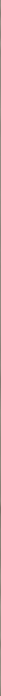


University of British Columbia Library

\section{DUE DATE SER IALS}

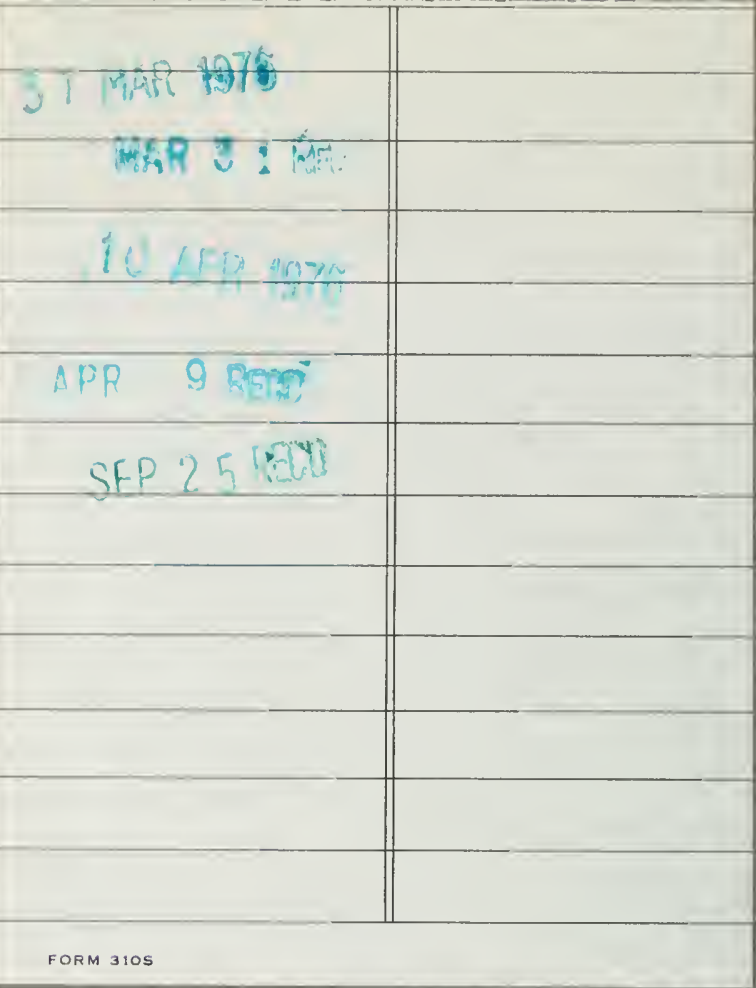


$A 1 \quad C 21$

1912

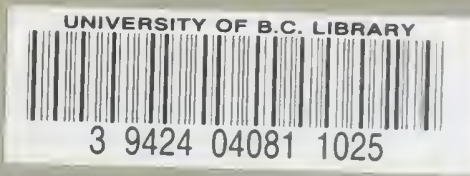


